\title{
A novel small molecule HSP90 inhibitor, NXD30001, differentially induces heat shock proteins in nervous tissue in culture and in vivo
}

\author{
Jieun R. C. Cha • Kyle J. H. St. Louis • Miranda L. Tradewell • \\ Benoit J. Gentil • Sandra Minotti - Zahara M. Jaffer • Ruihong Chen • \\ Allan E. Rubenstein • Heather D. Durham
}

Received: 2 September 2013 /Revised: 14 September 2013 / Accepted: 16 September 2013 / Published online: 3 October 2013

(C) Cell Stress Society International 2013

\begin{abstract}
Heat shock proteins (HSPs) are attractive therapeutic targets for neurodegenerative diseases, such as amyotrophic lateral sclerosis (ALS), characterized by aberrant formation of protein aggregates. Although motor neurons have a high threshold for activation of HSP genes, HSP90 inhibitors are effective inducers. This study evaluated NXD30001, a novel, small molecule HSP90 inhibitor based on the radicicol
\end{abstract}

Jieun R. C. Cha and Kyle J. H. St. Louis contributed equally to the manuscript.

Electronic supplementary material The online version of this article (doi:10.1007/s12192-013-0467-2) contains supplementary material, which is available to authorized users.

J. R. C. Cha • K. J. H. St. Louis • M. L. Tradewell • B. J. Gentil •

S. Minotti $\cdot$ H. D. Durham $(\bowtie)$

Montreal Neurological Institute and Department

of Neurology/Neurosurgery, McGill University,

3801 University St, Montreal, QC, Canada H3A 2B4

e-mail: heather.durham@mcgill.ca

Z. M. Jaffer $\cdot$ R. Chen $\cdot$ A. E. Rubenstein

NexGenix Pharmaceuticals Holdings, New York, NY 10019, USA

Present Address:

M. L. Tradewell

Miranda Writes Medical Communication,

Toronto, ON, Canada M6R 2B1

Present Address:

Z. M. Jaffer

House Research Institute, Los Angeles, CA 90057, USA

Present Address:

R. Chen

OncoSynergy, San Francisco, CA 94158, USA

Present Address:

A. E. Rubenstein

NYU Langone Medical Center, New York, NY 10019, USA backbone, for its ability to induce neuronal HSPs and for efficacy in an experimental model of ALS based on mutations in superoxide-dismutase 1 (SOD1). In motor neurons of dissociated murine spinal cord cultures, NXD30001-induced expression of HSP70/HSPA1 (iHSP70) and its co-chaperone HSP40/DNAJ through activation of HSF1 and exhibited a protective profile against $\mathrm{SOD} 1^{\mathrm{G} 93 \mathrm{~A}}$ similar to geldanamycin, but with less toxicity. Treatment prevented protein aggregation, mitochondrial fragmentation, and motor neuron death, important features of mutant SOD1 toxicity, but did not effectively prevent aberrant intracellular $\mathrm{Ca}^{2+}$ accumulation. NXD30001 distributed to brain and spinal cord of wild-type and SOD $1^{\mathrm{G} 93 \mathrm{~A}}$ transgenic mice following intraperitoneal injection; however, unlike in culture, in vivo levels of SOD1 were not reduced. NXD30001-induced expression of iHSP70 in skeletal and cardiac muscle and, to a lesser extent, in kidney, but not in liver, spinal cord, or brain, with either single or repeated administration. NXD30001 is a very useful experimental tool in culture, but these data point to the complex nature of $H S P$ gene regulation in vivo and the necessity for early evaluation of the efficacy of novel HSP inducers in target tissues in vivo.

Keywords HSP90 inhibitor · Heat shock proteins · Motor neurons $\cdot$ Spinal cord $\cdot$ Muscle $\cdot$ Amyotrophic lateral sclerosis $\cdot$ SOD1

\section{Introduction}

Amyotrophic lateral sclerosis (ALS) is a devastating and fatal neurodegenerative disorder, manifesting in adulthood and resulting predominantly from dysfunction and death of motor neurons in the cerebral cortex, brain stem and spinal cord. 
There is no sufficiently effective treatment, and death typically occurs within 3-5 years of diagnosis. About $90 \%$ of cases occur sporadically (sALS). The remainder are clearly familial (fALS; Valdmanis et al. 2009); the genetic loci identified include genes encoding $\mathrm{Cu} / \mathrm{Zn}$-superoxide dismutase (SOD1; Rosen et al. 1993), TAR DNA-binding protein 43 (Neumann et al. 2006; Arai et al. 2006), fused in sarcoma/ translated in liposarcoma (FUS; Kwiatkowski et al. 2009; Vance et al. 2009), vesicle-associated membrane protein B (Nishimura et al. 2004), ubiquilin2 (Deng et al. 2011), C9ORF72 (Renton et al. 2011; Dejesus-Hernandez et al. 2011), p62 (Hirano et al. 2013), profilin 1 (Daoud et al. 2013), and RGNEF, a rhoGEF nucleotide exchange factor (Droppelmann et al. 2013). Aside from sporadic ALS, this multiplicity of fALS-associated genes points to ALS being a syndrome with multiple initiating factors, yet there are commonalities in the manifestation of disease in patients with either familial or sporadic disease including formation of inclusions, unfolded protein responses, excitotoxicity, calcium dysregulation, mitochondrial dysfunction, oxidative stress, axonal transport defects, disruption of neuromuscular junctions, altered RNA metabolism, disruption of neuron-glia interactions, and inflammatory responses (Boillee et al. 2006).

Despite the multifactorial nature of disease pathogenesis, protein misfolding (due to mutation or post-translational modification) could represent an upstream, underlying process that is amenable to therapeutic intervention, in particular, upregulation of heat shock proteins (HSPs) with chaperoning activity. Upregulation of HSPs has resulted in significant protection in primary culture and transgenic mouse models of SOD1linked fALS (Bruening et al. 1999; Kieran et al. 2004; Batulan et al. 2006; Kalmar et al. 2008) and spinal bulbar muscular atrophy (Malik et al. 2013). The Durham Lab has been evaluating HSP inducers and other potential therapeutics in a primary culture model, which is created by expressing disease-causing mutant proteins in motor neurons of dissociated cultures of murine spinal cord-dorsal root ganglia (DRG; Durham et al. 1997; Roy et al. 1998; Bruening et al. 1999; Batulan et al. 2006; Tradewell et al. 2011). Expression of SOD1 mutants in cultured motor neurons, but not SOD1 ${ }^{\text {WT }}$, results in formation of inclusions containing the mutant protein, consistent with the inclusions formed in mutant SOD1 transgenic mice and ALS patients (Dal Canto and Gurney 1995; Bruijn et al. 1997; Shibata et al. 1993), and loss of viability over 1 to 2 weeks (Durham et al. 1997). A study examining early pathogenic events following expression of the mutant SOD $1^{\mathrm{G} 93 \mathrm{~A}}$ in this model showed an initial increase in mitochondrial $\left[\mathrm{Ca}^{2+}\right]$, followed by dramatic mitochondrial rounding and increased endoplasmic reticular $\left[\mathrm{Ca}^{2+}\right]$. This was followed by increased cytosolic $\left[\mathrm{Ca}^{2+}\right]$, which was significantly higher in neurons harboring inclusions of mutant protein (Tradewell et al. 2011). In addition, impaired mitochondrial dynamics, including inhibition of mitochondrial fusion and axonal transport, also occurred as an early event (this study and Magrane et al. 2012; Song et al. 2012).

HSP90 inhibitors are effective inducers of HSPs, presumably by releasing the major heat shock gene transcription factor, HSF1, which is held inactive in HSP90 complexes, such that it translocates to the nucleus, binds to heat shock promoter elements (HSE), and becomes activated to transactivate heat shock genes (Voellmy 2004). The HSP90 inhibitor, geldanamycin, induces expression of stressinducible HSP70/HSPA1 (iHSP70) and its co-chaperone HSP40/DNAJ in motor neurons and other spinal cord cells (Batulan et al. 2006). Geldanamycin treatment was highly effective in preventing the formation of mutant SOD1 inclusions and preserving mitochondrial morphology and motor neuron viability, although the impact on accumulation of $\mathrm{Ca}^{2+}$ in intracellular compartments was minimal (Batulan et al. 2006; Tradewell et al. 2011).

Because the pharmacokinetic/pharmacodynamic (PK/PD) profile and toxicity of geldanamycin make it unsuitable for in vivo administration, new compounds with reduced cytotoxicity and improved blood-brain barrier permeability are being developed. In this study, we evaluated NXD30001, a novel HSP90 inhibitor based on the radicicol backbone, from NexGenix Pharmaceuticals (New York, NY, USA; Barluenga et al. 2008, 2009; Wang et al. 2009; Zhu et al. 2010). We report that NXD30001 had a neuroprotective profile similar to geldanamycin in the ALS1 culture model, but with less toxicity. The PK analysis in mice showed the presence of NXD30001 in the central nervous system and other tissues, with particularly high levels in liver and muscle, making it potentially useful for in vivo administration. However, regardless of the tissue concentration of the drug, iHSP70 was induced only in skeletal and cardiac muscle and, to a lesser extent, in kidney, but not in brain, spinal cord, or liver.

\section{Materials and methods}

\section{Dissociated spinal cord-DRG cultures}

Cultures were prepared from E13 CD1 mouse embryos and cultured in hormone- and growth factor-enriched medium, and motor neurons were identified as previously described (Roy et al. 1998). Cultures were used in experiments 3-6 weeks following dissociation to allow maturation of motor neurons. All studies were carried out in accordance with the Canadian Council on Animal Care.

\section{Gene transfer}

Plasmid expression vectors were microinjected into motor neuronal nuclei as previously described at concentrations leading to protein expression in at least $90 \%$ of injected 
neurons (Durham et al. 1997). Unless fluorescent protein tags were incorporated into the plasmid sequence, $20 \mathrm{mg} / \mathrm{ml} 70$ dextran-fluorescein FITC (Molecular Probes, Eugene, OR, USA) was included in the injectate to identify injected neurons.

Plasmids: Human SOD $1^{\text {WT }}$ or the ALS-causing mutant, SOD $1^{\mathrm{G} 93 \mathrm{~A}}$, in pCEP4 or pcDNA3 (injected at 200 and $60 \mu \mathrm{g} / \mathrm{ml}$, respectively); eGFP-SOD $1^{\text {WT }}$ or eGFP-SOD $1^{\mathrm{G} 93 \mathrm{~A}}$ in eGFPN1 (injected at $4 \mu \mathrm{g} / \mathrm{ml}$; Tradewell et al. 2011); eGFPN1 (injected at $2 \mu \mathrm{g} / \mathrm{ml}$ ); inactive HSF1 deletion mutant

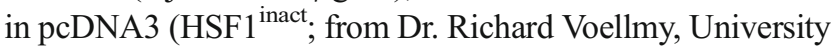
of Miami, Miami FL, USA; injected at $5 \mu \mathrm{g} / \mathrm{ml})$; mitochondrial targeted ratiometric pericam (mtpericam; from Dr. Atsushi Miyawaki, RIKEN Brain Science Institute, Wako City, Saitama, Japan; injected at $25 \mu \mathrm{g} / \mathrm{ml}$ ); pOCTeGFP or pOCTdsRed in pcDNA3 (with the mitochondrial targeting signal sequence of ornithine carbamoyltransferase; from Dr. Heidi McBride, McGill University, Montreal, QC, Canada; injected at $2.5-13 \mu \mathrm{g} / \mathrm{ml}$ ); photoactivatable eGFP in pcDNA3 (PA-OCTeGFP from Dr. Richard Youle, NINDS, Bethesda, MD, USA; injected at $23 \mu \mathrm{g} / \mathrm{ml}$ ).

Drug treatment in culture

Stock solutions of NXD30001 (10 mM, NexGenix Pharmaceuticals; M.W. 477) and geldanamycin (5 mM, StressMarq Biosciences, Victoria BC, Canada) were prepared in dimethyl sulfoxide (DMSO) and aliquots were stored at $-80^{\circ} \mathrm{C}$. The maximal concentration of DMSO used was $0.0025 \%$ (for 250 nM NXD30001), a concentration previously shown not to be cytotoxic to motor neurons in our studies or to interfere with AMPA receptor function (Tsvyetlynska et al. 2005). Stock was diluted in culture medium to working concentrations. The structure of NXD30001 was previously published as pochoxime A (Barluenga et al. 2009).

\section{Immunocytochemistry and SDS-PAGE/Western blotting of cultures}

For immunocytochemistry (ICC), spinal cord-DRG cultures on coverslips were fixed in $3 \%$ paraformaldehyde in phosphate buffered saline (PBS) for $10 \mathrm{~min}$, permeabilized with $0.5 \%$ Nonidet-P40 in PBS for $1 \mathrm{~min}$, fixed again with paraformaldehyde for $2 \mathrm{~min}$, blocked with $5 \%$ horse serum in PBS for $30 \mathrm{~min}$, incubated with the primary antibody for $1 \mathrm{~h}$, washed with PBS three times for $5 \mathrm{~min}$ each, incubated with secondary antibody for $30 \mathrm{~min}$, washed with PBS three times for $5 \mathrm{~min}$ each, and mounted on glass slides using Immumount (Fisher Scientific, Mississauga, ON, Canada).

For SDS-PAGE/Western blotting, cultures on 18-mmdiameter coverslips were washed with cold PBS and harvested in $100 \mu \mathrm{l}$ of $20 \mathrm{mM}$ Tris $/ 2 \mathrm{mM}$ ethylenediaminetetraacetic acid. Harvested cells were sonicated for $3 \mathrm{~s}$ at $50 \%$ cycle duty using a Vibro Cell Sonicator (Sonics and Materials, Danbury, CT, USA). Supernatants were collected after centrifugation at $13,000 \times \mathrm{g}$ at $4{ }^{\circ} \mathrm{C}$ for $5 \mathrm{~min}$. Protein concentration was determined by DC Protein Assay (Bio-Rad Life Science, Mississauga, ON, Canada). Samples containing 7.5 or $15 \mu \mathrm{g}$ of protein were loaded onto 15-well SDS-polyacrylamide gels (12.5\% acrylamide for detection of HSPs; $8 \%$ for detection of multiple forms of HSF $1 ; 4 \%$ acrylamide stacking gels). Gels were blotted onto nitrocellulose and probed as indicated, using actin or glyceraldehyde-3-phosphate dehydrogenase (GAPDH) as loading control.

Antibodies: Human SOD1 was detected by immunocytochemistry (ICC) using mouse monoclonal antibody SD-G6 (Sigma Chemical, St. Louis, MO, USA; 1:300) and on Western blots using rabbit SOD-100 antibody (Enzo Life Sciences, Brockville, ON, Canada; 1:1,000). Antibodies used for the detection of HSPs were: Mouse monoclonal against iHSP70 [Enzo Life Sciences, Framingdale, NY, USA SPA-810; 1:100 for ICC, 1:1,000 for Western blotting (WB)], rabbit antiHSP40 (Enzo Life Sciences SPA-400; 1:3000 for ICC, 1:10, 000 for WB), goat anti-HSP25/27 (Santa Cruz Biotechnology, Santa Cruz, CA, USA SC-1049; 1:500 for WB), rabbit antiHSP60 (Santa Cruz SC-13966; 1:500 for WB), and rabbit antiHSP90 (Santa Cruz SC-7947, clone\# H-114; 1:1,000 for WB). For the Western blot analysis of HSF1 activation, monoclonal rat anti-HSF1 (Enzo Life Sciences SPA-950, clone\# 10H8; 1:1, 000 for WB) was used. Mouse anti- $\beta$-actin (MP Biomedicals, Solon, OH, USA; $1: 10,000$ for WB) and rabbit anti-GAPDH (ABCAM Cambridge, MA, USA; 1:3,000 for WB) antibodies were used for loading controls. Secondary antibodies for ICC were: anti-mouse IgG-Alexa Flour 488 (Molecular Probes; 1:200), anti-rabbit IgG-Alexa Flour 594 (Molecular Probes; 1:200), and anti-mouse IgG-Cy3 (Molecular Probes; 1:300). For WB, the following secondary antibodies were used: peroxidase conjugated donkey-anti-goat IgG (Jackson Immunoresearch Laboratories, Westgrove PA, USA; 1:3,000), sheep-anti-mouse IgG-peroxidase (Jackson Immunoresearch; 1:3,000), donkey-anti-rabbit IgG-peroxidase (Jackson Immunoresearch; 1:3000), and goat anti-rat IgG-peroxidase (EMD, Mississauga, ON, Canada; 1:3000). Peroxidase activity was visualized using Pierce ECL chemiluminescent substrate (Thermo Fisher Scientific).

Imaging of epifluorescence

Cultures (living or fixed and mounted on slides) were placed on the stage of an Axiovert 35 inverted microscope (Carl Zeiss Canada, Toronto, ON, Canada) equipped with epifluorescence optics and a Lambda 10-B/SmartShutter ${ }^{\mathrm{TM}}$ and Lambda 10-C filter wheel (Sutter Instruments, Novato, CA, USA) containing excitation and emission filters (Chroma Technologies, Rockingham, VT, USA). Images, below fluorescence 
saturation level, were captured using an ORCA-ER cooled CCD digital camera (Hamamatsu Photonics, Hamamatsu City, Japan) and analyzed using Universal MetaFluor ${ }^{\mathbb{B}^{2}}$ Imaging Software (Molecular Devices, Downingtown, PA, USA). Fluorescence intensity in defined regions was quantified using Metafluor ${ }^{\circledR}$.

\section{Assays of mitochondrial function}

Mitochondrial transport, length, and fusion were assayed as previously described (Gentil et al. 2011). Mitochondrial transport: Motor neurons were microinjected with pOCT-eGFP plus empty plasmid or plasmid encoding SOD ${ }^{\mathrm{WT}}$ or $\mathrm{SOD} 1^{\mathrm{G} 93 \mathrm{~A}}$. After 3 days, coverslips were placed in a live cell imaging chamber (Harvard Apparatus, Montreal, Canada) and mounted on the stage of the Zeiss Axiovert 35 microscope. Images were captured using a $63 \times 1.4$ NA Apochromat objective using the ORCA-ER cooled CCD camera and Metafluor ${ }^{\circledR}$ software. Images were acquired every $5 \mathrm{~s}$ for 100 frames $(8 \mathrm{~min})$. Deconvolution was performed using 3-D Huygens deconvolution software (Scientific Volume Imaging, Hilversum, The Netherlands). Universal Imaging Metamorph ${ }^{\circledR}$ software (Molecular Devices) was used to generate videos and kymographs of mitochondrial position, from which movement was assessed as anterograde, retrograde, or stationary. Movement was defined as at least $4 \mu \mathrm{m}$ change in position over four's honestly significant difference (HSD) test, with significance established at $p<0.05$.

For measurement of mitochondrial length, cultures were fixed in $4 \%$ paraformaldehyde in PBS, and then images of eGFP epifluorescence in axonal segments of motor neurons were transferred to NIH ImageJ software to measure lengths of individual mitochondria. Significance of difference between means of two groups was analyzed by unpaired $t$ test with significance established at $p<0.05$.

Mitochondrial fusion was assessed using the technique of Karbowski et al. (2004). Mitochondrial targeted, photoactivatable (PA) eGFP and mitochondrial targeted dsRed were co-expressed in motor neurons by intranuclear microinjection of PA-OCT-eGFP and pOCT-dsRed plasmids. eGFP was photoactivated by exciting an 18 pixels-diameter region of interest (ROI) with a $405 \mathrm{~nm}$ laser (3 ROI/neuron). eGFP and dsRed images were acquired using an LSM510 confocal microscope (Carl Zeiss) before and immediately after activation, and after an additional 30 and $60 \mathrm{~min}$. Mean fluorescence units (FU) for each ROI at each time point was expressed as a percentage of the intensity immediately after activation, with inclusion of measurements from only those ROIs in which the dsRed fluorescence intensity was maintained over time (to exclude changes in eGFP fluorescence due to movement of mitochondria out of the ROI). Pseudocolor images were recorded using LSM Image Browser (Carl Zeiss). Measurements were included from a minimum of 15 ROI (in 7-10 motor neurons) per condition. Statistical analysis was performed by one-way ANOVA followed by the Tukey's honestly significant difference (HSD) test, with significance established at $p<0.05$.

\section{Mitochondrial and cytosolic $\mathrm{Ca}^{2+}$}

Mitochondrial $\left[\mathrm{Ca}^{2+}\right]$ was measured as previously described (Tradewell et al. 2011) using the genetically-encoded, mitochondrial targeted sensor, mtpericam (Shimozono et al. 2002). The mtpericam was excited alternately through $436 / 10$ and $494 / 18 \mathrm{~nm}$ filters and fluorescence emission was collected at $535 / 30 \mathrm{~nm} . \mathrm{Ca}^{2+}$ binding causes an increase in excitation at $494 \mathrm{~nm}$ and decrease in excitation at $436 \mathrm{~nm}$; thus, the ratio of fluorescence at $494 / 436$ is directly proportional to mitochondrial $\left[\mathrm{Ca}^{2+}\right]$. Experimental data were obtained from at least three separate coverslips per condition and repeated in at least two different culture batches. Normalization of data across experiments was carried out by dividing each 494/436 ratio by the overall mean of the experiment. This was conducted in order to combine data obtained on separate days (necessary due to a low $n$ per day). Significance of difference between group means was assessed by unpaired, two-tailed $t$ test, with significance established at $p<0.05$. After the experiment, cultures were fixed and immunolabeled with antibody to human SOD1 (SD-G6) to confirm plasmid expression.

Cytosolic $\left[\mathrm{Ca}^{2+}\right]$ was measured using the ratiometric indicator, fura-2 (Molecular Probes; used at $10 \mu \mathrm{M}$ ) as previously described (Tradewell et al. 2011). fura- 2 was excited alternately using 340/10 and 380/10 nm filters and emission through a long-pass $510 \mathrm{~nm}$ filter was captured by Metafluor ${ }^{\circledR}$. Cytosolic $\left[\mathrm{Ca}^{2+}\right]$ was determined as the ratio of fluorescence at 340/380 nm excitation. Data for each experimental group were collected using the same parameters within the same experiment. Significance of difference between group means was assessed by unpaired $t$ test, with significance established at $p<0.05$.

Quantitation of neurons with inclusions

Motor neurons were microinjected with plasmid encoding SOD $1^{\mathrm{G} 93 \mathrm{~A}}$ and cultures were treated with vehicle or NXD30001. After 3 days, cultures were fixed and immunolabeled with antibody specific to human SOD1 (SD-G6; this antibody does not cross-react with murine SOD1, thus only detects human SOD1 derived from plasmid). The percentage of motor neurons with aggregated $\mathrm{SOD} 1^{\mathrm{G} 93 \mathrm{~A}}$ was calculated in three cultures per condition and expressed as mean \pm SEM. Significance of difference between means was evaluated by 
unpaired $t$ test, with significance established at $p<0.05$. Note, SOD $1^{\text {WT }}$ does not form these inclusions and therefore was not evaluated in this experiment (Durham et al. 1997).

\section{Motor neuron viability}

Viability of motor neurons was evaluated at days 1-5 inclusive, following microinjection of expression plasmids plus the $70 \mathrm{kDa}$ dextran-FITC. The number of neurons containing the marker was counted by epifluorescence microscopy and morphology was evaluated by phase microscopy. Counts were normalized to the number of neurons on day 1 as previously described (Roy et al. 1998). Viability curves were obtained by plotting the values (mean number of surviving motor neurons \pm SEM) obtained from life tables analysis in SPSS. Significance of differences among means was calculated using logrank test in SPSS, with significance established at $p<0.05$. A minimum of three cultures per condition was evaluated and the experiment was repeated using at least one additional culture batch.

\section{Transgenic mice}

C57BL6-TgN(SOD1 $\left.{ }^{\text {G93A }}\right)$ 1Gur, transgenic for human SOD1 with the ALS-associated mutation G93A and nontransgenic littermates were used in this study. Initial breeders were obtained from the Jackson Laboratory (Bar Harbor, ME, USA). Lines were maintained in the animal facility at the Montreal Neurological Institute and mice hemizygous for the transgene were obtained by breeding hemizygous males with nontransgenic C57BL6 females. All experiments were approved by the McGill University Animal Care Committee and followed the guidelines of the Canadian Council on Animal Care. Mice were genotyped for human SOD1 according to the JAX protocol. SOD $1^{\mathrm{G} 93 \mathrm{~A}}$ transgenic mice were designated "symptomatic" by positive hind- limb extensor reflex (approximately at 140 days of age).

Mice (three per group) were injected intraperitoneally (i.p.) with 50, 100, or $150 \mathrm{mg} / \mathrm{kg}$ NXD30001 in $10 \%$ DMSO, $5 \%$ Tween 20, $15 \%$ CremaphorEL, and $70 \%$ saline, either as a single dose or repeated three times weekly for 2 weeks, as indicated in the "Results" section.

\section{Tissue levels of NXD30001}

Mice were euthanized by deep anesthesia with i.p. injection of ketamine/xylazine 1 or $6 \mathrm{~h}$ after the last injection. Blood was obtained by cardiac puncture (EDTA anticoagulant), followed by perfusion with normal saline. Brain, spinal cord, liver, kidney, heart, and skeletal muscle (quadiceps) were harvested and samples were divided in two for separate analysis of drug level and HSP expression. Plasma and tissues were placed immediately on ice and then frozen and stored at $-80{ }^{\circ} \mathrm{C}$.
Plasma and tissue levels of NXD30001 were analyzed under subcontract to Cerep (Redmond,WA, USA). Each tissue sample was homogenized in $0.75 \mathrm{ml}$ cold PBS, pH 7.4 for 10 seconds on ice using Power Gen 125. The homogenized tissue was then stored at $-20{ }^{\circ} \mathrm{C}$ until further processing. NXD30001 was extracted from plasma and tissue homogenates using acetonitrile precipitation. Calibration standards $(1-5000 \mathrm{ng} / \mathrm{ml})$ were generated by spiking 2.5 or $10 \mu \mathrm{l}$ of each $20 \times$ standard solution of the test compound into 47.5 or $190 \mu \mathrm{l}$ of drug-free plasma or tissue homogenate, respectively. The spiked samples were processed together with the unknown samples. Briefly, $200 \mu$ of acetonitrile was added to each $50 \mu \mathrm{l}$ plasma sample, and $400 \mu \mathrm{l}$ of acetonitrile was added to each $200 \mu$ sample of tissue homogenate. Samples were mixed for $5 \mathrm{~min}$ on the plate shaker and then centrifuged at $6,000 \times g$ for $15 \mathrm{~min}$ at $4{ }^{\circ} \mathrm{C}$. Supernatant, containing the compound, was transferred into a new tube and was centrifuged at $3,900 \times \mathrm{g}$ for $15 \mathrm{~min} .20 \mu \mathrm{l}$ of the supernatant was subject to LCMS analysis. A Gemini NX C18 column $(2 \times 50 \mathrm{~mm}, 5 \mu \mathrm{m})$ was used (Phenomenex). The mobile phase A was $12 \mathrm{mM}$ ammonium formate $/ 6 \mathrm{mM}$ formic acid in water and the mobile phase $\mathrm{B}$ was $6 \mathrm{mM}$ ammonium formate $/ 3 \mathrm{mM}$ formic acid in water/MeOH $(1 / 9, \mathrm{v} / \mathrm{v})$. The flow rate was $0.5 \mathrm{ml} / \mathrm{min}$ and the gradient was $60 \% \mathrm{~B}$ for $0.5 \mathrm{~min}, 60$ $100 \% \mathrm{~B}$ in $1.5 \mathrm{~min}$, and $100 \% \mathrm{~B}$ for $0.9 \mathrm{~min}$. TSQ Quantum was used for MS/MS analysis.

\section{Analysis of HSP expression in tissues}

Ice-cold excised tissue samples were homogenized in $2 \%$ SDS sample buffer (20 mM Tris, $2 \mu \mathrm{M}$ EDTA) containing protease inhibitor cocktail (Roche, Mississauga, ON, Canada) using a $2 \mathrm{ml}$ Wheaton hand homogenizer. Tissue homogenates were sonicated for $5 \mathrm{~s}$ at $50 \%$ cycle using a Vitro Cell Sonicator and centrifuged at $15,000 \times \mathrm{g}$ for $15 \mathrm{~min}$. Supernatants were collected and sample protein concentrations were determined using the Bradford protein assay. $25 \mu \mathrm{g}$ of protein from each sample was prepared with Laemmli loading buffer containing $\beta$-mercaptoethanol and were boiled for $5 \mathrm{~min}$.

Protein samples were separated using SDS-PAGE (10\% acrylamide resolving gel, $4 \%$ acrylamide stacking gel) at $100 \mathrm{~V}$. Separated proteins were transferred to a nitrocellulose membrane at $100 \mathrm{~V}$ at $4{ }^{\circ} \mathrm{C}$ for $1 \mathrm{~h}$ followed by $30 \mathrm{~V}$ at $4{ }^{\circ} \mathrm{C}$ overnight. Transfer efficiency was assessed using Ponceau protein staining. Following transfer, the nitrocellulose membranes were blocked for $30 \mathrm{~min}$ at room temperature using $5 \%$ skim milk in TBS. The blocked membranes were probed with primary antibody overnight at $4{ }^{\circ} \mathrm{C}$ and with horseradish peroxidase (HRP)-conjugated secondary antibody for $45 \mathrm{~min}$ at room temperature. The membranes underwent three 15 -min washes in $0.3 \%$ Tween-TBS after each probing. HRP activity was stimulated by HyGlo Chemiluminescent HRP 
detection reagent purchased from Denville Scientific (Metuchen, NJ, USA).

\section{Results}

NXD30001-induced expression of iHSP70 and HSP40 in cultured motor neurons by activating HSF 1

Initial studies established the dose-response activity of NXD30001 for upregulating HSPs and whether this occurred through activation of the major mammalian heat shock transcription factor, HSF1 (Voellmy 2004). Treatment of mouse spinal cord-DRG cultures with 10-250 nM NXD30001 resulted in dose-related expression of iHSP70 and of HSP40. 40 nM NXD30001 consistently induced expression of iHSP70 and HSP40 above control levels. This is comparable to treatment with geldanamycin, another HSP90 inhibitor (Fig. 1a). HSP90, mitochondrial HSP60, and HSP25 levels were not altered by either drug. At the exposures used in these experiments, NXD30001 did not show signs of cytotoxicity and thus exhibited a greater margin between iHSP70-inducing a
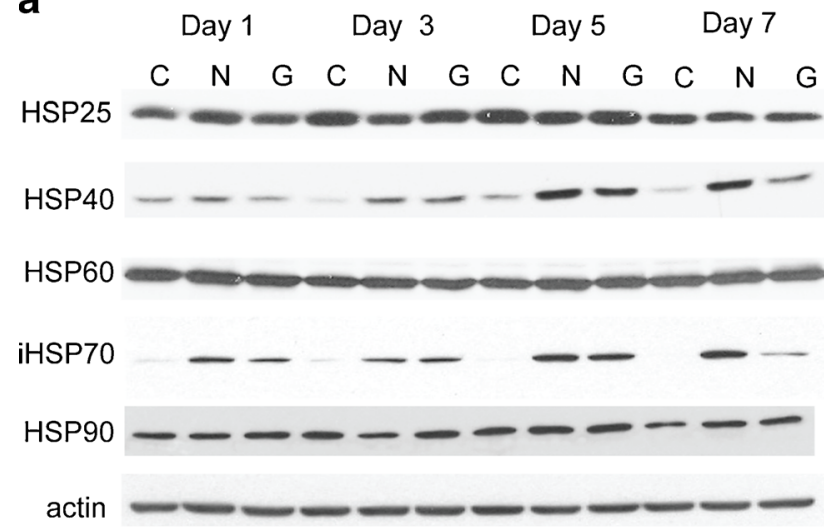

b
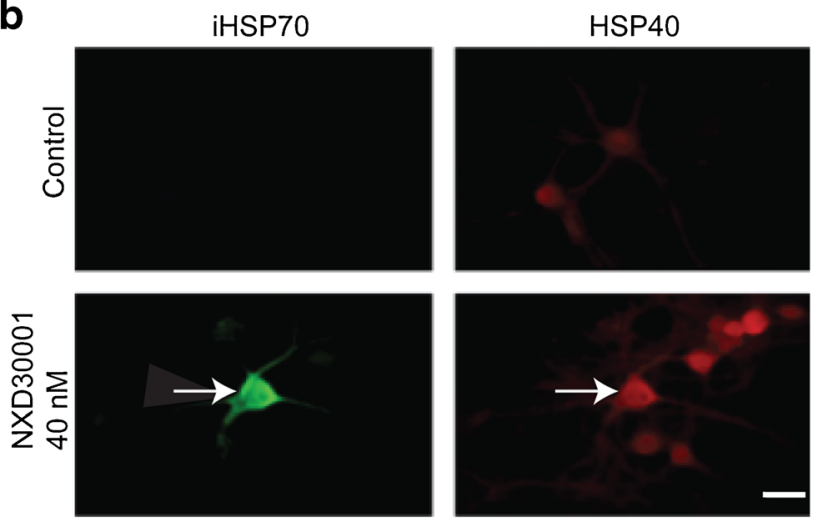

C

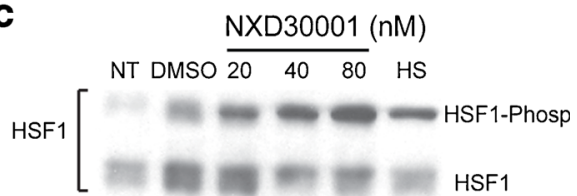

iHSP70

actin
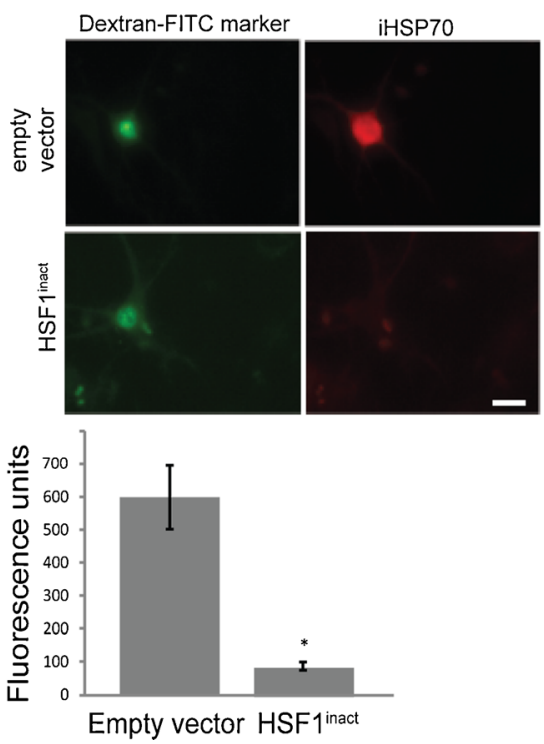

Fig. 1 NXD30001-induced expression of HSPs in spinal cord-DRG cultures in a dose-, time- and HSF1-dependent manner. a Western blots of spinal cord-DRG cultures treated with vehicle $[C], 40 \mathrm{nM}$ NXD30001 $[N]$, or $20 \mathrm{nM}$ geldanamycin $[G]$ for $1,3,5$, or 7 days probed with antibodies to individual HSPs and actin as loading control. Both drugs induced persistent expression of iHSP70/HSPA1 and HSP40/DNAJ, but not HSP25, HSP60, or HSP90. b Double-label immunocytochemistry of spinal cord-DRG cultures with antibodies to iHSP70 (left images) and HSP40 (right images) after 3 days treatment with $40 \mathrm{nM}$ NXD30001 or vehicle. The concentration of HSP40 antibody was reduced to minimize labeling of endogenous HSP40 in cultures treated with vehicle (upper right image). Note strong induction of $\mathrm{iHSP} 70$ and HSP40 in the motor neuron marked by the arrow. Additional motor neurons in this field have increased HSP40, but not iHSP70 (lower right image). Scale bar $=20 \mu \mathrm{m}$. (c) Upper panel: Dose-dependent increase in activation of HSF1 and expression of iHSP70 with NXD30001 treatment. Western blot analysis of spinal cord-DRG cultures treated with regular culture medium (NT), DMSO (vehicle-control), NXD30001 (20-80 nM), or heat-shocked (HS; $43^{\circ} \mathrm{C}$ for $30 \mathrm{~min}$ ) and probed with antibodies to HSF1, iHSP70, and actin as loading control. Note increased density of the higher molecular weight bands detected by the HSF1 antibody, representing phosphorylation of HSF1 associated with activation. The small increase in HSF1 in the vehicle-treated culture was not accompanied by iHSP70 expression. Middle and lower panels: Suppression of NXD30001-induced iHSP70 expression by a constitutively inactive (dominant negative) HSF1 mutant $\left(H S F 1^{\text {inact }}\right)$. Motor neurons of spinal cord-DRG cultures were microinjected with dextran-FITC (inert fluorescent marker) along with empty pcDNA3 vector or vector encoding HSF $1^{\text {inact }}$, then treated for 3 days with $40 \mathrm{nM}$ NXD30001. Cultures were fixed and immunolabeled with antibody to iHSP70. Shown in the middle panel are: the dextranFITC marker (left) and labeling of iHSP70 (right) in a representative motor neuron. Motor neurons expressing $\mathrm{HSF}_{1}{ }^{\text {inact }}$ did not express iHSP70. Scale bar $=20 \mu \mathrm{m}$. Lower panel: $\mathrm{iHSP} 70$ expression was quantified as FU in 17-20 motor neurons per condition using Metafluor ${ }^{\circledR}$ imaging software and graphed as means \pm SEM. iHSP70 expression was significantly suppressed in motor neurons injected with $H S F 1^{\text {inact }}$ plasmid $\left({ }^{*} p<0.0001\right)$ 
a

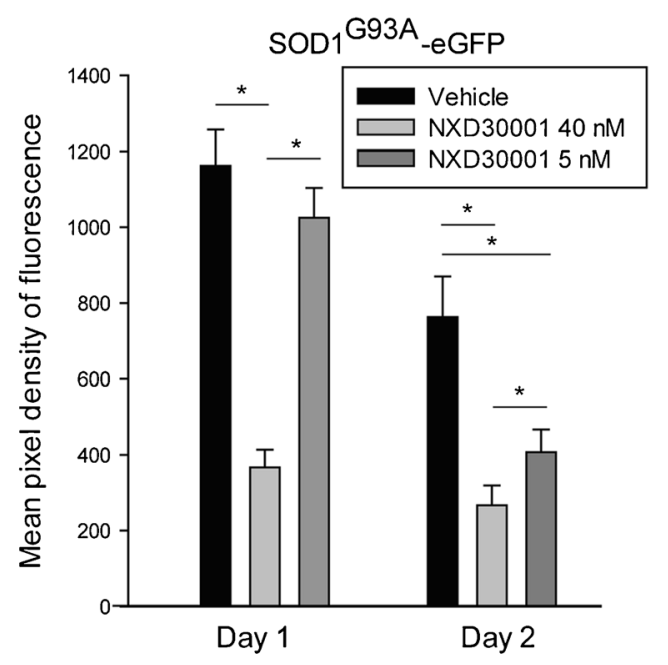

b
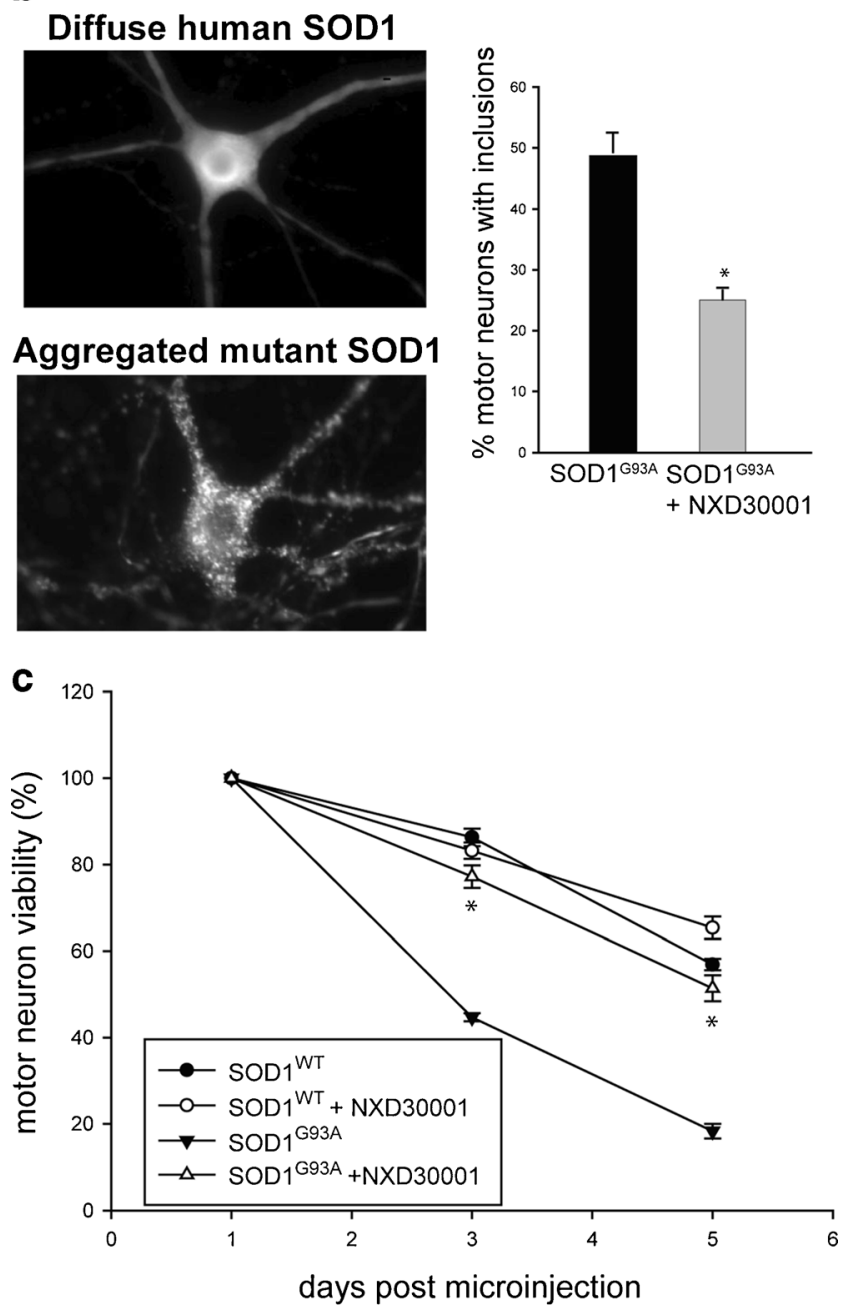

and cytotoxic concentrations compared to its parent compound, radicicol, or to geldanamycin (Batulan et al. 2006). Both iHSP70 and HSP40 were induced in motor neurons within the cultures (Fig. 1b). After 3 days of treatment with $40 \mathrm{nM}$ NXD30001, an average of $81.2 \pm 1.27 \%$ motor neurons (mean \pm SEM)
4 Fig. 2 a NXD30001 reduced levels of SOD1 ${ }^{\mathrm{G} 93 \mathrm{~A}}$-eGFP. NXD30001 $(40 \mathrm{nM})$ significantly reduced the levels of SOD1 ${ }^{\mathrm{G} 93 \mathrm{~A}}$-eGFP on both days relative to vehicle ( $0.0004 \%$ DMSO). On day 2, both 40 and $5 \mathrm{nM}$ NXD30001 treatment groups showed significant reduction in SOD ${ }^{\text {G93A }}$-eGFP levels. Shown are means \pm SEM of data from 31-95 neurons and two cultures per group. b $40 \mathrm{nM}$ NXD30001 significantly reduced formation of mutant SOD1 inclusions. Human SOD 1 WT or SOD $1^{\mathrm{G} 93 \mathrm{~A}}$ were expressed in motor neurons by intranuclear microinjection of plasmid plus the marker, dextran-FITC. Plasmidderived protein was detected by immunocytochemistry with antibody recognizing human, but not endogenous murine, SOD1. SOD ${ }^{\mathrm{WT}}$ remains diffusely distributed (upper image), whereas a proportion of motor neurons expressing mutant protein contain SOD1immunolabeled inclusions (lower image). Graphed is the mean percentage of SOD $1^{\mathrm{G} 93 \mathrm{~A}}$-expressing neurons containing inclusions (mean $\pm \mathrm{SEM}, n=3$ ) in cultures treated with $40 \mathrm{nM}$ NXD30001 3 days. c Treatment with $40 \mathrm{nM}$ NXD30001 prolonged viability of motor neurons expressing SOD $1^{\mathrm{G} 93 \mathrm{~A}}$. Presented are means \pm SEM of results from three cultures per condition, 20-60 motor neurons/culture (*significantly different at $p<0.05$ )

expressed iHSP70, as detected by immunocytochemistry. After 7 days, an average of $61.1 \pm 2.71 \%$ of motor neurons expressed iHSP70 (data from three culture batches). iHSP70 expression induced by NXD30001 in motor neurons was HSF1-dependent (Fig. 1c): hyperphosphoryation of HSF1, an indicator of HSF1 activation required for transactivation of $h s p$ genes, was detected by Western analysis (upper panel) and suppression of iHSP70 was achieved by expression of an inactivatable, dominant negative form of HSF1 (middle and lower panels).

NXD30001 reduced accumulation of mutant SOD1 and formation of inclusions and maintained motor neuron viability

Accumulation of mutant SOD1 in motor neurons results in protein aggregation and formation of inclusions. Fig. 2a shows that treatment with $40 \mathrm{nM}$ NXD30001 delayed accumulation of SOD1 $1^{\mathrm{G} 93 \mathrm{~A}}$-eGFP in motor neurons, but not of SOD $1{ }^{\text {wt }}$-eGFP or eGFP. Cultures containing plasmid-injected motor neurons were incubated in regular culture medium, medium containing DMSO $0.0004 \%$, or $40 \mathrm{nM}$ NXD30001 and the levels of eGFP fluorescence in motor neurons were quantified as described in the "Materials and methods" section. Treatment with $40 \mathrm{nM}$ NXD30001 reduced the accumulated level of SOD $1^{\mathrm{G} 93 \mathrm{~A}}$-eGFP on both day 1 and day 2 $(p<0.0001$ for both days), whereas $5 \mathrm{nM} \mathrm{NXD30001} \mathrm{signif-}$ icantly reduced SOD $1^{\mathrm{G} 93 \mathrm{~A}}$-eGFP only on day $2(p<0.001)$. Delayed accumulation of SOD $1^{\mathrm{G} 93 \mathrm{~A}}$-eGFP was most likely through enhanced degradation rather than altered transcription or translation because SOD $1^{\mathrm{WT}}$-eGFP and eGFP were expressed from the same CMV promoter.

Treatment with NXD30001 also significantly reduced the formation of SOD1-containing inclusions (Fig. 2b) and prolonged viability of motor neurons expressing $\mathrm{SOD} 1^{\mathrm{G} 93 \mathrm{~A}}$ to those expressing SOD1 ${ }^{\mathrm{WT}}$ (Fig. 2c) 
a

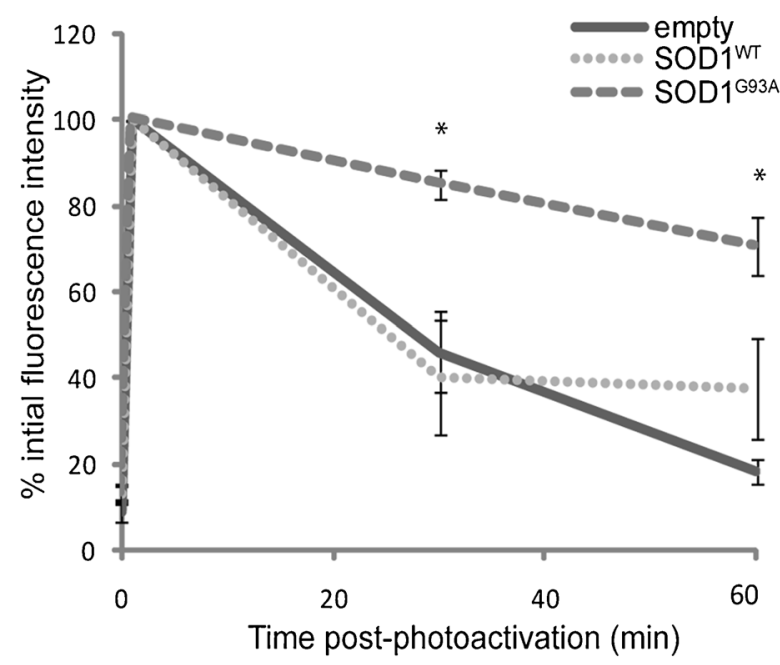

b

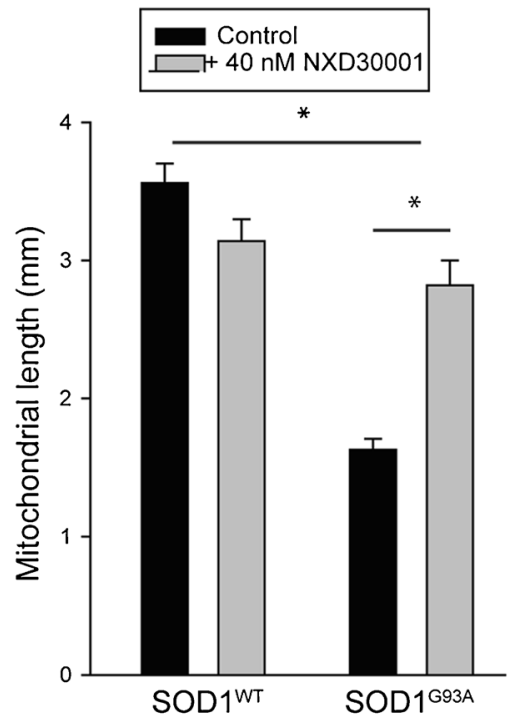

d

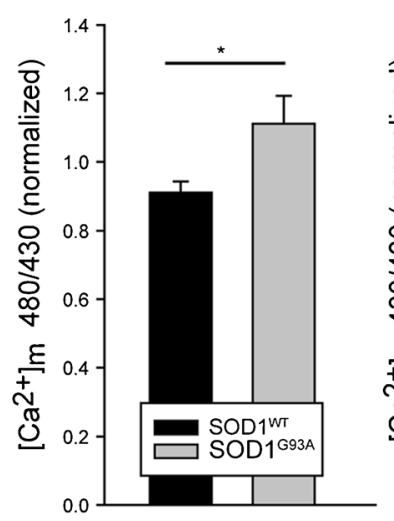

Mitochondrial $\mathrm{Ca}^{2+}$

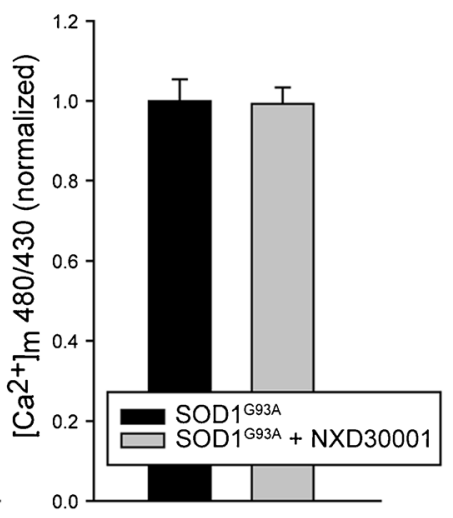

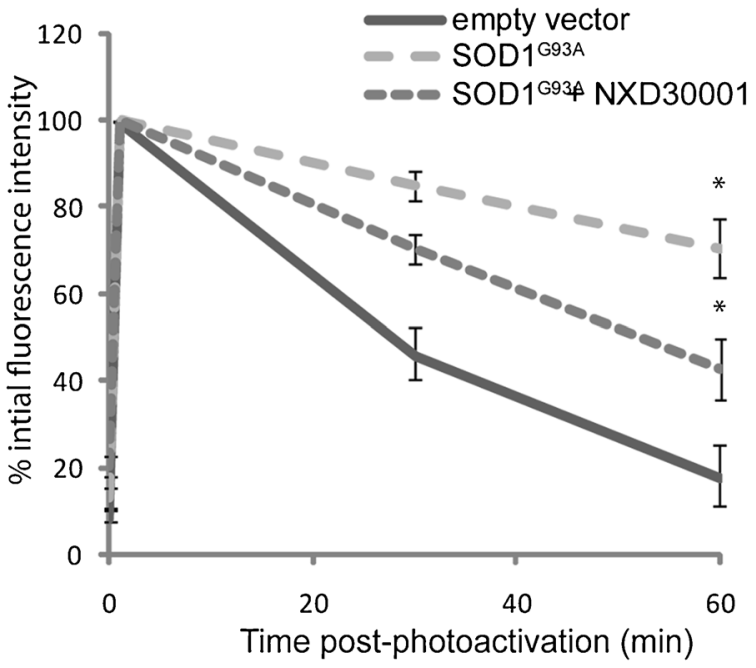

c

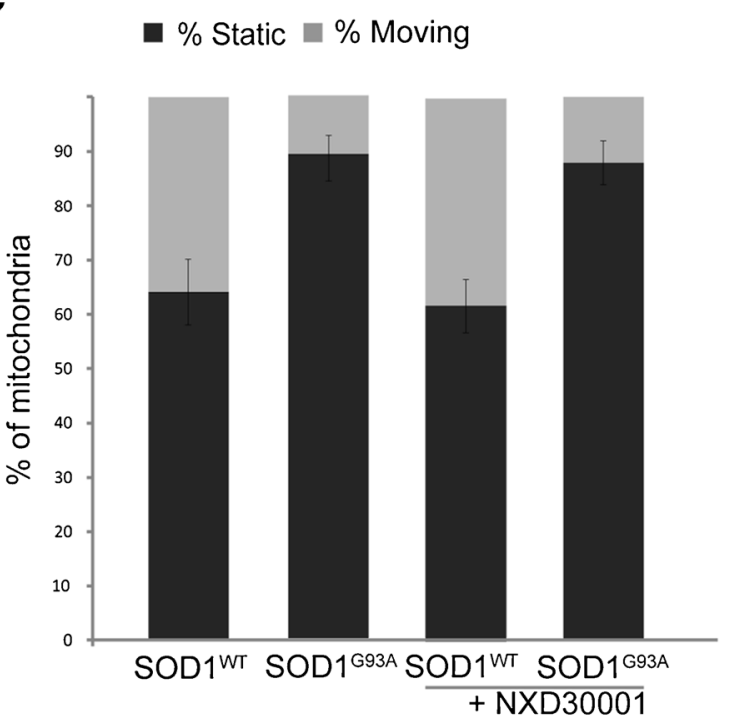

e Cytosolic $\mathrm{Ca}^{2+}$
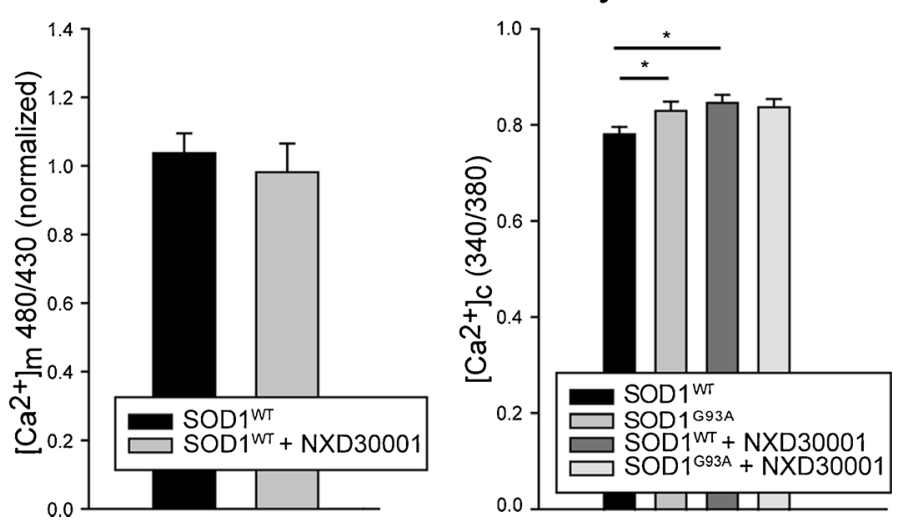
4 Fig. 3 NXD30001 preserved mitochondrial fusion and morphology (length), but not axonal transport or intracellular $\mathrm{Ca}^{2+}$ homeostasis in motor neurons expressing mutant SOD1. Motor neurons in dissociated spinal cord-DRG cultures were microinjected with plasmid encoding WT or G93A mutant SOD1 and treated with $40 \mathrm{nM}$ NXD30001 or vehicle for 3 days, when a mitochondrial fusion, $\mathbf{b}$ mitochondrial rounding/ fragmentation (measured as mitochondrial length), $\mathbf{c}$ axonal transport of mitochondria, d mitochondrial $\mathrm{Ca}^{2+}$, and e cytosolic $\mathrm{Ca}^{2+}$ were measured. SOD $1^{\mathrm{G} 93 \mathrm{~A}}$ impaired mitochondrial fusion and transport, caused mitochondrial fragmentation, and increased mitochondrial and cytosolic $\mathrm{Ca}^{2+}$. Presented are means \pm SEM of results from three cultures per condition, 20-60 motor neurons/culture (*significantly different at $p<0.05$ )

NXD30001 preserved mitochondrial fusion and morphology, but not calcium homeostasis in motor neurons expressing $\mathrm{SOD} 1^{\mathrm{G} 93 \mathrm{~A}}$

Mitochondrial rounding/fragmentation was an early manifestation of SOD $1^{\mathrm{G} 93 \mathrm{~A}}$ toxicity in cultured motor neurons, preceding increase in cytosolic $\mathrm{Ca}^{2+}$ and formation of inclusions (Tradewell et al. 2011). Mitochondrial morphology is influenced by the balance of fusion/fission (Cheung et al. 2007) and the mitochondrial rounding in motor neurons expressing mutant SOD1 was associated with impairment of fusion dynamics (Fig. 2a). Treatment with $40 \mathrm{nM}$ NXD30001 significantly reduced the impaired fusion resulting from $\mathrm{SOD} 1^{\mathrm{G} 93 \mathrm{~A}}$ expression, which was quantified as decrease in fluorescence over time of photoactivated, mitochondrially targeted eGFP in regions of interest as described in the "Materials and methods" section. Data for all experimental groups obtained at $60 \mathrm{~min}$ of the fusion assay are summarized in Fig. 3a, clearly illustrating the protective effect of NXD30001 for maintaining mitochondrial fusion. Mitochondrial rounding/fragmentation induced by $\mathrm{SOD} 1^{\mathrm{G} 93 \mathrm{~A}}$ also was prevented (Fig. 3b). Thus, NXD30001 maintained mitochondrial morphology in motor neurons expressing mutant SOD1 by maintaining the balance of fusion/fission.

Inhibition of mitochondrial axonal transport is a significant aspect of SOD $1{ }^{\mathrm{G} 93 \mathrm{~A}}$ toxicity (see Tradewell et al. 2011). Since mitochondria move in spurts, transport was quantified as the percent of mitochondria moving or stationary during an observation period. Treatment with NXD30001 did not prevent the impairment of transport in neurons expressing SOD1 ${ }^{\mathrm{G} 93 \mathrm{~A}}$ (Fig. 3c).

Early accumulation of mitochondrial and endoplasmic reticular $\mathrm{Ca}^{2+}$ and eventually cytosolic $\mathrm{Ca}^{2+}$ are prominent features of SOD ${ }^{\mathrm{G} 93 \mathrm{~A}}$ in this culture model, which were not prevented by the HSP90 inhibitor, geldanamycin (Tradewell et al. 2011). Similarly, NXD30001 failed to prevent the increase in mitochondrial or cytosolic $\mathrm{Ca}^{2+}$ in motor neurons expressing SOD $1^{\mathrm{G} 93 \mathrm{~A}}$ (Fig. 3d).

In summary, NXD30001 had a good profile of neuroprotection in a primary culture model of ALS1, inducing HSPs at noncytotoxic concentrations and protecting against some of the hallmark features of SOD $1^{\mathrm{G} 93 \mathrm{~A}}$ toxicity.

PK/PD profile of NXD30001 and induction of HSPs in vivo

Having established the profile of HSP induction by NXD30001 in neural cultures, the compound's PK/PD profile was investigated in vivo. Studies by NexGenix Pharmaceuticals had established i.p. administration as the best route of administration, oral availability being very low (see Electronic Supplementary Material Table A1). Data from a preliminary PK experiment demonstrated central nervous system (CNS) exposure after a single i.p. administration of $100 \mathrm{mg} / \mathrm{kg}$ of NXD30001 in mice (see Electronic Supplementary Material Table A2). In brain, drug concentration reached well above $40 \mathrm{nM}$ (the therapeutic concentration used in the culture model of ALS1, equivalent to $20 \mathrm{ng} / \mathrm{g}$ tissue).

We proceeded to evaluate tissue distribution of NXD30001 and induction of HSPs using mice transgenic for human SOD1 ${ }^{\mathrm{G} 93 \mathrm{~A}}$, an established model for preclinical evaluation of therapeutics for ALS, and in wild-type mice of their C57BL6 background. Other studies by NexGenix had established that a dosing schedule of $50 \mathrm{mg} / \mathrm{kg}$ of drug three times per week could be administered in these mice without clinical toxicity, although up to $100 \mathrm{mg} / \mathrm{kg}$, three times per week i.p. administration could be tolerated for a few weeks (unpublished data). NXD30001 had anti-tumor activities in xenograft and transgenic models, associated with increased

Table 1 NXD30001 accumulated in murine tissues including CNS

\begin{tabular}{|c|c|c|c|c|c|}
\hline Animal & $\begin{array}{l}\text { Plasma } \\
\text { (ng/ml) }\end{array}$ & $\begin{array}{l}\text { Brain } \\
(\mathrm{ng} / \mathrm{g})\end{array}$ & $\begin{array}{l}\text { Spinal cord } \\
(\mathrm{ng} / \mathrm{g})\end{array}$ & $\begin{array}{l}\text { Liver } \\
\text { (ng/g) }\end{array}$ & $\begin{array}{l}\text { Muscle } \\
\text { (ng/g) }\end{array}$ \\
\hline \multicolumn{6}{|c|}{ NXD300001 tissue levels: 1-h postadministration } \\
\hline Mouse 36/6 & 455 & 810 & 815 & 9930 & 1812 \\
\hline Mouse 36/8 & 246 & 254 & 290 & 5451 & 12208 \\
\hline Mouse 36/9 & 189 & 219 & 256 & 4791 & 2182 \\
\hline \multicolumn{6}{|c|}{ NXD30001 tissue levels: 6-h postadministration } \\
\hline Mouse 36/1 & 18 & 68 & 501 & 3921 & 330 \\
\hline Mouse 36/2 & 12 & 247 & 339 & 410 & 632 \\
\hline Mouse 36/4 & 14 & 105 & 124 & 2347 & 253 \\
\hline
\end{tabular}

Early symptomatic SOD1 ${ }^{\mathrm{G} 93 \mathrm{~A}}$ transgenic mice were dosed i.p. with $50 \mathrm{mg} / \mathrm{kg} \mathrm{NXD30001} \mathrm{on} \mathrm{a} \mathrm{three} \mathrm{times} \mathrm{per} \mathrm{week} \mathrm{schedule} \mathrm{for} 2$ weeks. Mice were euthanized 1 or $6 \mathrm{~h}$ after the last dose. Various tissues were collected and NXD30001 concentrations were measured by LC/MS. Drug concentrations were higher at $1 \mathrm{~h}$ (upper panel) than $6 \mathrm{~h}$ (lower panel) in all tissues. In plasma, NXD30001 cleared quickly and reached near the lower limit of quantitation level at $6 \mathrm{~h}$. In contrast, NXD30001 levels in brain, spinal cord, liver, and muscle were still above the neuroprotective concentration used in culture ( $40 \mathrm{nM}$, equivalent to $20 \mathrm{ng} / \mathrm{g}$ of tissue) at $6 \mathrm{~h}$, despite substantial decrease from levels at $1 \mathrm{~h}$. Drug levels in liver and muscle were much higher than those in nervous tissues. To convert ng/g to molar concentration, multiply by 0.5 
a

Brain

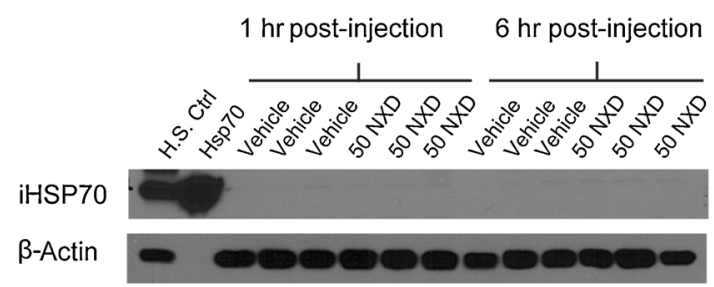

C

Liver

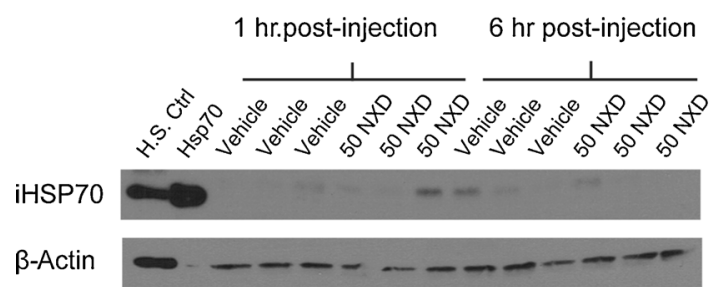

Fig. 4 Induction of iHSP70 expression in quadiceps muscle of symptomatic SOD1 ${ }^{\mathrm{G} 93 \mathrm{~A}}$ transgenic mice, but not in CNS (brain or lumbar spinal cord) or in liver following dosing with $50 \mathrm{mg} / \mathrm{kg}$ NXD30001 (50 $N X D$ ) or vehicle i.p. three times per week for 2 weeks (tissue levels of drug were analyzed in the same mice; see Table 1). Tissues were

turnover of cell signaling molecules that are HSP90 client proteins (Barluenga et al. 2008, 2009; Wang et al. 2009; Zhu et al. 2010; Tanaka et al. 2013).

NXD30001 drug levels were measured in plasma, brain, lumbar spinal cord, skeletal muscle, and liver from symptomatic $\mathrm{SOD} 1^{\mathrm{G} 93 \mathrm{~A}}$ transgenic mice that had been dosed three times weekly with $50 \mathrm{mg} / \mathrm{kg}$ of drug or vehicle over 2 weeks (3 mice/ group). Tissues were excised at 1 and $6 \mathrm{~h}$ time points following the last dose. NXD30001 levels in plasma, brain, lumbar spinal cord, skeletal muscle, and liver are shown in Table 1. NXD30001 cleared quickly from plasma. In brain and spinal cord, NXD30001 reached concentrations well above the therapeutic range in culture at both time points, with the maximum concentrations ranging from 459 to $1698 \mathrm{nM}$ at $1 \mathrm{~h}$ in brain and from 536 to $1709 \mathrm{nM}$ at $1 \mathrm{~h}$ in spinal cord; however, much higher concentrations of drug were detected in liver and muscle.

Tissues from the same mice were analyzed for expression of iHSP70 and other HSPs (HSP90, HSP40, HSP60, and HSP25) for expression and activation of the major heat shock transcription factor, HSF1, and levels of SOD1. No iHSP70 expression was detected in any samples of brain, spinal cord or liver, but upregulation was observed in quadriceps muscle harvested at both 1- and 6-h postinjection of $50 \mathrm{mg} / \mathrm{kg}$ NXD30001 (Fig. 4). No consistent increase in other HSPs was noted, with the exception of elevated HSP25 in 1-h spinal cord samples, which did not reach statistical significance (Fig. 5).

Consistent with data in culture. induction of iHSP70 appeared to be HSF1-dependent. Gel shift of HSF1, indicating hyperphosphorylation/activation, was observed only in muscle b Lumbar Spinal Cord

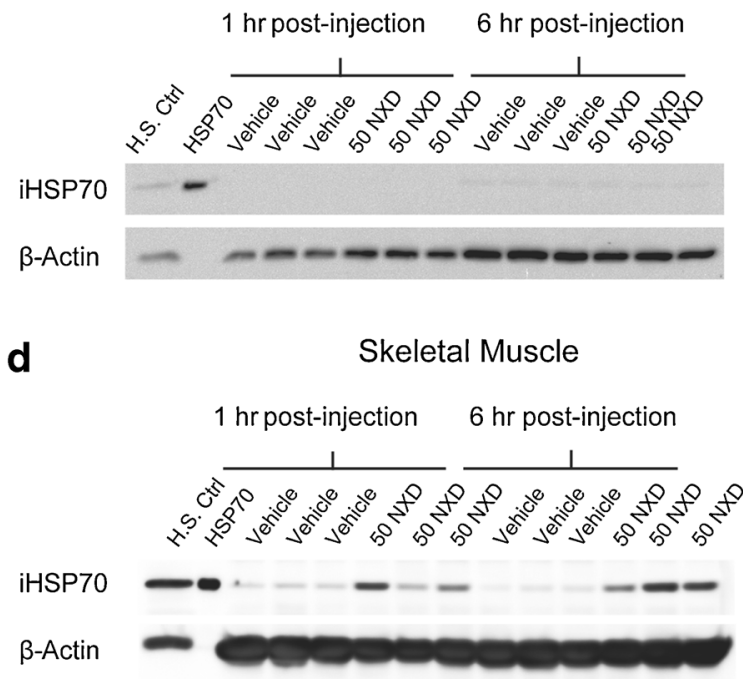

harvested at 1 or $6 \mathrm{~h}$ after injection of the last dose. Total tissue extracts were subjected to Western analysis with antibody against iHSP70 and $\beta$ actin as loading control. Extracts of heat-shocked spinal cord-DRG cultures (H.S. Ctrl) and recombinant iHSP70 (Hsp70) were run as positive controls

harvested at the 1-h time point, although iHSP70 expression was significantly elevated in the 6-h samples (Fig. 5).

In culture, NXD30001 treatment delayed accumulation of mutant SOD1, but no reduction in SOD1 was measured in spinal cord or muscle of treated mice. To the contrary, SOD1 was increased in spinal cord, statistically significant in the 6-h samples (Fig. 5). An additional higher molecular weight immunoreactive band was detected in 1-h spinal cord samples, even in vehicle treated mice, and was included in the quantitation.

The dose-response and time-course for HSP induction by NXD30001 was further investigated in wild type C57BL6 mice. Mice were administered 50 or $100 \mathrm{mg} / \mathrm{kg}$ NXD30001 i.p. and tissues were harvested at time points up to $72 \mathrm{~h}$ later. iHSP70 was detected in samples of skeletal and cardiac muscle of NXD30001-treated mice harvested at 16, 36, and $72 \mathrm{~h}$ posttreatment (Fig. 6a-c). No iHSP70 or HSP25 was detected in 4-h samples (data not shown). Weak induction of iHSP70

Fig. 5 Treatment with NXD30001 caused transient phosphorylation/ activation of HSF1 (actHSF1) and induction of iHSP70 in quadriceps muscle, but not in spinal cord of symptomatic SOD $1^{\mathrm{G} 93 \mathrm{~A}}$ transgenic mice; transient increase in HSP25 in some spinal cord samples, but not muscle; and increase, rather than decrease in spinal cord SOD1. Mice were administered $50 \mathrm{mg} / \mathrm{kg}$ NXD30001 or vehicle i.p. three times per week for 2 weeks and tissues (lumbar spinal cord and quadriceps muscle) were harvested at 1 or $6 \mathrm{~h}$ after injection of the last dose (the same mice as in Fig. 4 and Table 1). Western blots of total tissue extracts were probed with antibodies to HSF1 and to HSP90, iHSP70, HSP60, HSP40, HSP25, and SOD1. Extracts of heat-shocked spinal cord-DRG cultures (H.S. $\mathrm{Ctrl}$ ) and recombinant iHSP70 (HSP70) were run as positive controls 
a

\section{Lumbar Spinal Cord}

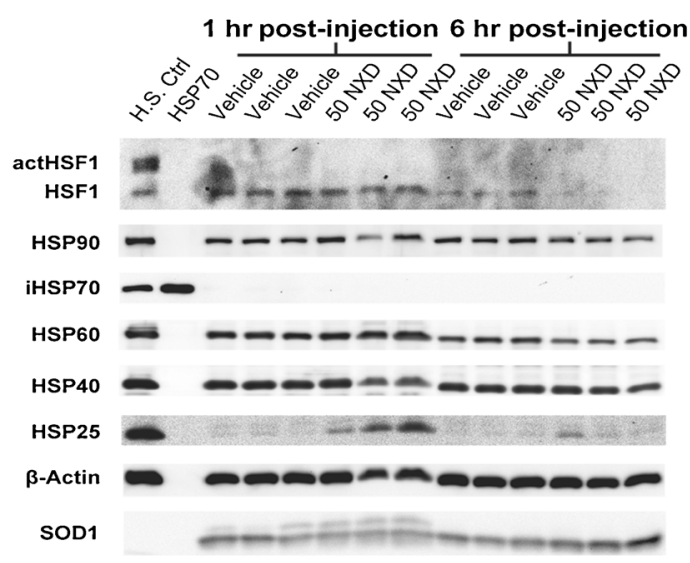

b
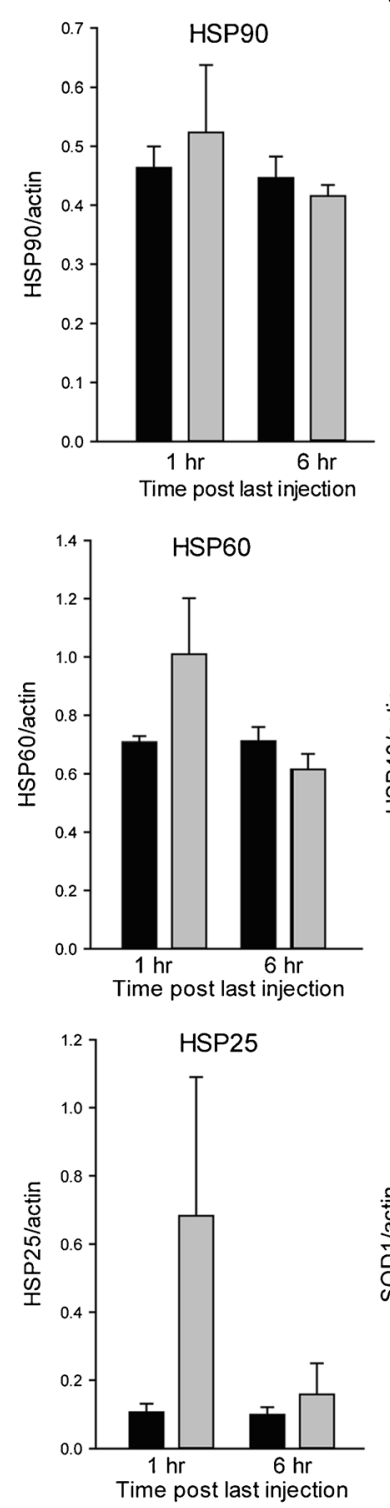

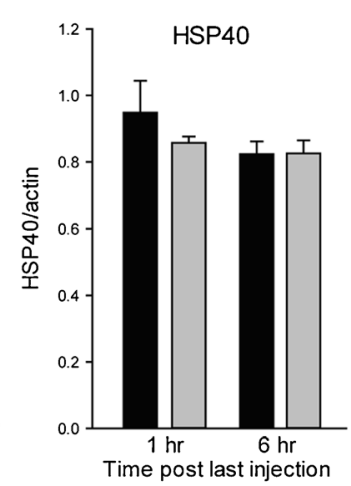

vehicle NXD30001

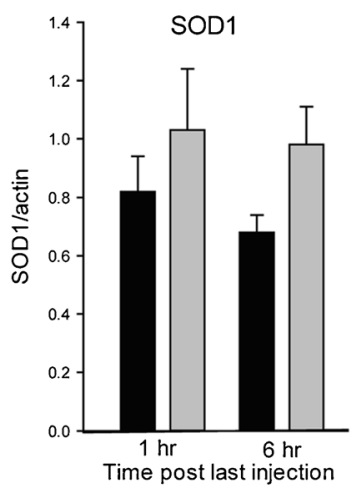

Skeletal Muscle

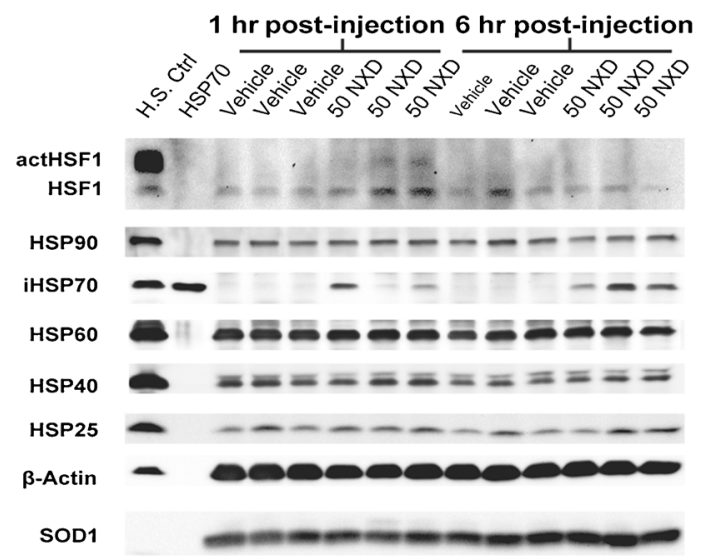

Skeletal Muscle
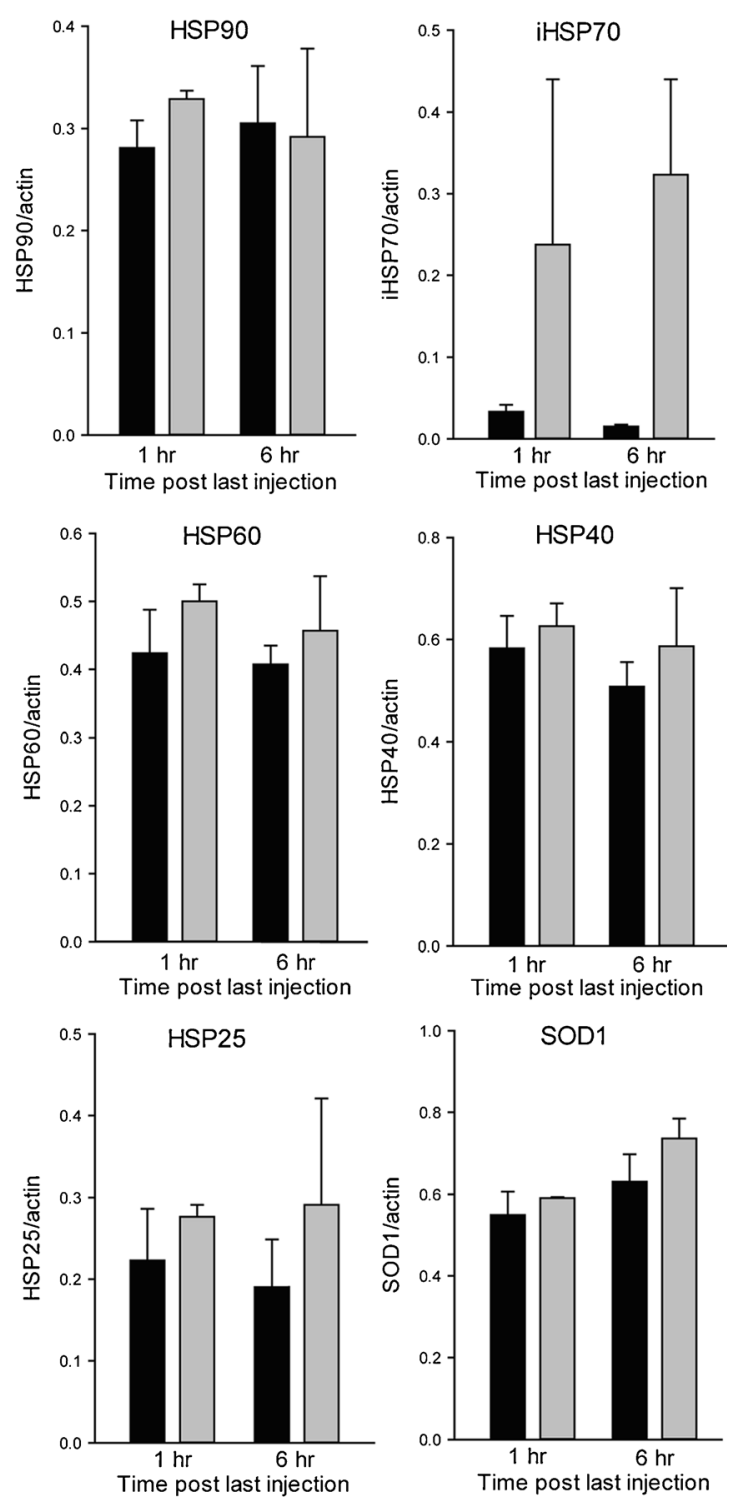
a
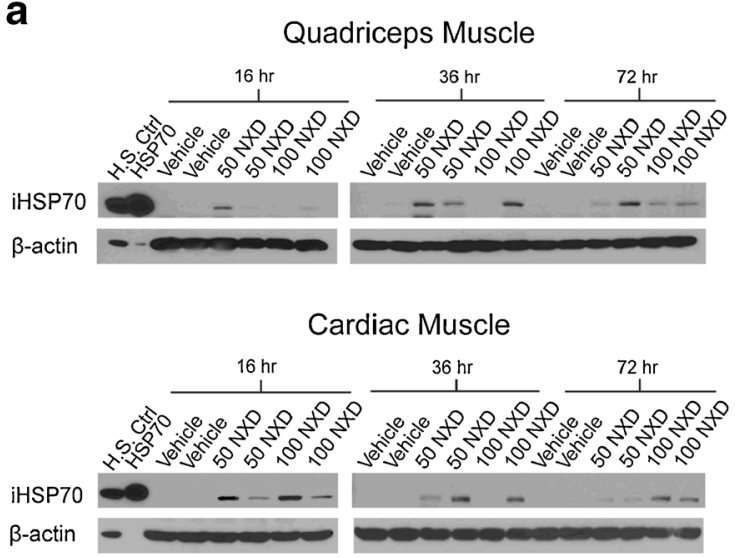

C

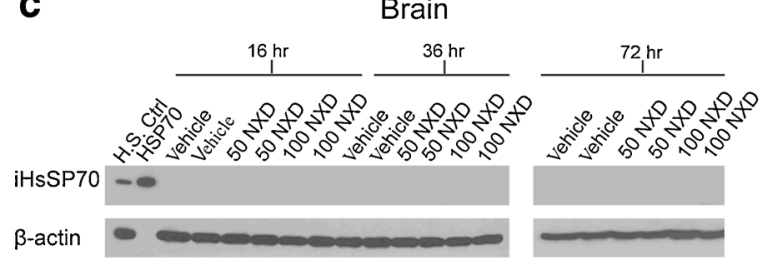

Lumbar Spinal Cord

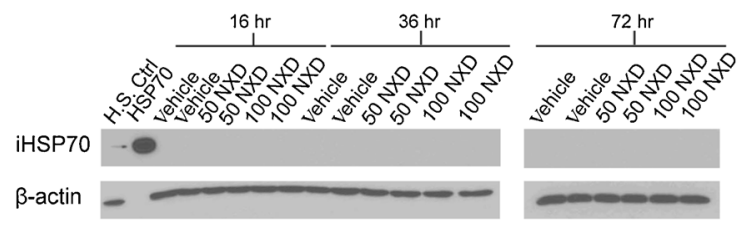

Liver

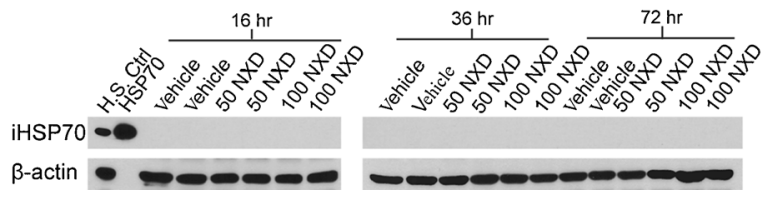

Fig. 6 Single dose i.p. administration of NXD30001-induced expression of iHSP70 in skeletal and cardiac muscle and to a lesser extent in kidney, but not in nervous tissue or liver of wild-type C57BL6 mice. Tissues were harvested at 16, 36, or $72 \mathrm{~h}$ after the injection. Shown are Western blots of

was observed in kidney in the 16-h samples; however, no increase in iHSP70 expression was detected in brain, lumbar spinal cord, or liver in this experiment, nor in brain or lumbar spinal cord of mice treated with $150 \mathrm{mg} / \mathrm{kg}$, the upper limit of solubility and tolerability (Fig. 6d). Upregulation of iHSP70 in quadriceps and cardiac muscle also occurred in $\mathrm{SOD} 1^{\mathrm{G} 93 \mathrm{~A}}$ transgenic mice after single dose administration of NXD30001 (data not shown).

In summary, despite biodistribution to the CNS and induction of iHSP70 expression in skeletal and cardiac muscle, NXD30001 failed to activate HSF1 or induce multiple HSPs in the CNS even after administration at doses that would not be compatible with long-term administration. b

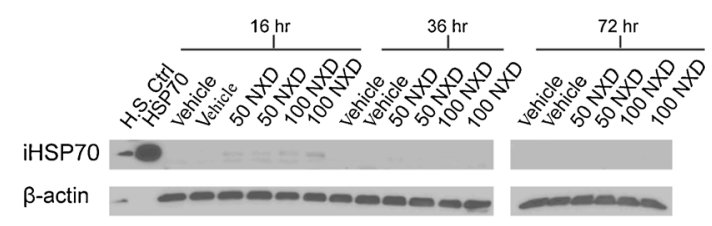

d

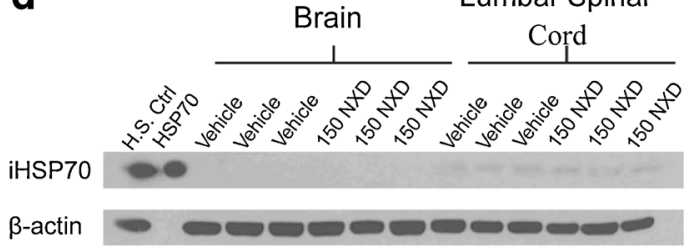

total tissue extracts probed with antibodies to iHSP70 and $\beta$-actin as loading control. Extracts of heat-shocked spinal cord-DRG cultures (H.S. $\mathrm{Ctrl}$ ) and recombinant iHSP70 (HSP70) were run as positive controls

\section{Discussion}

Toxicity of mutant SOD1 is complex, involving multiple intracellular pathways, even though the initial cause is a single missense mutation. Mutations are thought to promote protein misfolding and inappropriate interactions with multiple macromolecules. Protein chaperoning activity, reflecting the cellular ability to maintain protein conformation, (Bruening et al. 1999; Tummala et al. 2005) and proteasome activity, reflecting reserve capacity to catabolize misfolded proteins, (Kabashi et al. 2004; Cheroni et al. 2005, 2009; Kabashi et al. 2008) are preferentially compromised in vulnerable regions of spinal cord in SOD $1^{\mathrm{G} 93 \mathrm{~A}}$ transgenic mice, a model of fALS due to 
SOD1 mutation. Similar proteasomal abnormalities were identified in postmortem spinal cord tissue from patients with sALS (Kabashi et al. 2012). Thus, the increased demands on protein chaperoning and degradation pathways are important contributors to pathogenesis and targets for therapeutic intervention. This approach has been limited by the availability of effective drugs with good CNS bioavailability and safety profile. NexGenix Pharmaceuticals had been developing a class of small molecule inhibitors of HSP90 based on the radicicol backbone as cancer therapeutic agents. Since a lead compound, NXD30001, showed distribution to the CNS, the utility for treatment of neurological protein conformation disorders was examined.

In primary spinal cord cultures, NXD30001 showed a similar profile of HSP induction and neuroprotection against mutant SOD1 in a primary culture model of familial ALS as previously shown for geldanamycin, i.e., inducing iHSP70 and HSP40, preventing formation of inclusions and motor neuron death as well as maintaining mitochondrial morphology (Bruening et al. 1999; Batulan et al. 2006; Tradewell et al. 2011). NXD30001 preserved mitochondrial morphology by preserving the balance of mitochondrial fusion/fission but, like geldanamycin, failed to prevent inhibition of mitochondrial transport, a calcium-dependent process, or the accumulation of mitochondrial and cytosolic $\mathrm{Ca}^{2+}$ that appears to be upstream of and to potentiate aggregation of mutant SOD1. The improved efficacy of NXD30001 in inducing HSPs compared to the parent compound, radicicol, and the reduced cytotoxicity compared to geldanamycin (Batulan et al. 2006) make this compound a useful tool for experimental studies in culture.

A different profile was observed following in vivo administration of NXD30001. Although PK analysis showed that NXD30001 distributed to the CNS as well as peripheral tissues after i.p. injection into mice, no induction of HSPs was detected in brain or spinal cord with the possible exception of a transient increase in HSP25 with multiple dosing. No iHSP70 expression was detected in nervous tissue despite the peak concentration of NXD30001 in CNS reaching and surpassing the effective concentration in culture, and despite pushing the dosage to the limit (based on solubility, the irritant properties of the vehicle and known toxicity with long-term administration).

The threshold for NXD30001-mediated HSP induction varies with tissue or cell type in vivo, since iHSP70 was routinely induced in cardiac and skeletal muscle at much lower tissue levels than liver, which accumulated the highest drug levels, but without drug-related HSP induction. Possible explanations include differences in cell uptake, kinetics of HSP90 complexes, or gene transactivation. The transcription factor HSF1 is important for induction of HSPs by NXD30001. Phosphorylation of HSF1, indicative of activation, was measured in spinal cord-DRG cultures following treatment with NXD30001, and NXD30001-induced iHSP70 expression in cultured motor neurons was prevented by expressing a dominant negative form of HSF1. Activation of HSF1 was also concordant with expression of iHSP70 in mouse muscle after in vivo administration. Note that another HSP90 inhibitor, HSP990, was effective in inducing iHSP70 in nervous tissue of mice, but the efficacy desensitized over time (Labbadia et al. 2011) due to chromatin changes that affected accessibility of HSF 1 to HSPEs.

NXD30001 did delay accumulation of SOD $1^{\mathrm{G} 93 \mathrm{~A}}$-eGFP in cultured motor neurons, without affecting SOD1 ${ }^{\text {WT }}$-eGFP or eGFP alone. Although this effect was dose-related similarly to induction of iHSP, HSP90 inhibitors promote degradation of client proteins by mechanisms other than HSP induction (Waza et al. 2005). Inhibition of HSP90 releases proteins from HSP90 complexes, with multiple consequences relevant to this discussion. One consequence is that HSPs in the complexes become available to chaperone misfolded proteins, including mutant SOD1, client protein degradation depending on HSP70-mediated ubiquitination and delivery to the proteasome. Secondly, the transcriptions factor, HSF1 is freed to translocate to the nucleus, where it can be activated to transactivate heat shock genes. However, no reduction in SOD1 occurred with 2 weeks of administration to SOD1 ${ }^{\text {G93A }}$ transgenic mice; rather SOD1 was elevated in spinal cord $6 \mathrm{~h}$ after the last injection of NXD30001 relative to samples from vehicle-treated mice. Appearance of a higher molecular weight band labeled by anti-SOD1 in 1-h samples of both vehicle alone and with NXD30001-treated mice suggests short-term toxicity of the vehicle or injection procedure. Although not investigated, this band could be a posttranslationally modified or crosslinked form of mutant SOD1.

Although the results were disappointing for testing NXD30001 in CNS disorders, the induction of iHSP70 in skeletal and cardiac muscle points to potential utility of HSP inducers in muscle disorders such as inclusion body myopathy. Interestingly, an HSP co-inducer, BPG-15, was recently reported to be effective in a mouse model of muscular dystrophy (Gehrig et al. 2012).

In conclusion, these studies point to the complexity of HSF1 regulation of heat shock genes and important considerations in exploiting this pathway therapeutically for chronic disease. HSP inducers are highly effective in preserving many, but not all, pathways known to be affected in ALS1. Thus, they could be particularly useful in combination therapies and should be evaluated in models of other forms of ALS.

Acknowledgments This work was supported by the Canadian Institutes for Health Research (MOP-77743 to HDD); the Muscular Dystrophy Association (MDA93897 to HDD); and the National Institutes of Health (1R21NS066129-01 to RC and HDD). The authors thank Laura Cooper for technical assistance, Dr. Richard Voellmy for the HSF $1^{\text {inact }}$ plasmid, Dr. Heidi McBride for pOCT-eGFP/dsRed plasmids, Atsushi Miyawaki for the mitochondrial pericam plasmid, and Dr. Richard Youle for the photoactivatable (PA)-pOCT-eGFP plasmid. The data were included in the M.Sc. theses of JRCC and KJHSL. 
Declarations Z. Jaffer, R. Chen and A. Rubenstein were employees of NexGenix Pharmaceuticals.

\section{References}

Arai T, Hasegawa M, Akiyama H, Ikeda K, Nonaka T, Mori H, Mann D, Tsuchiya K, Yoshida M, Hashizume Y, Oda T (2006) TDP-43 is a component of ubiquitin-positive tau-negative inclusions in frontotemporal lobar degeneration and amyotrophic lateral sclerosis. Biochem Biophys Res Commun 351:602-611

Barluenga S, Wong C, Fontaine JG, Aouadi K, Beebe C, Tsutsumi S, Neckers L, Winssinger N (2008) Divergent synthesis of a pochonin library targeting HSP90 and in vivo efficacy of identified inhibitor. Angew Chem Int Ed Engl 47:4432-4435

Barluenga S, Fontaine JG, Wang C, Aouadi K, Chen R, Beebe K, Neckers L, Winssinger N (2009) Inhibition of HSP90 with pochoximes: SAR and structure-based insights. Chembiochem 10: 2753-2759

Batulan Z, Taylor DM, Aarons RJ, Minotti S, Doroudchi MM, Nalbantoglu J, Durham HD (2006) Induction of multiple heat shock proteins and neuroprotection in a primary culture model of familial amyotrophic lateral sclerosis. Neurobiol Dis 24:213-225

Boillee S, Vande VC, Cleveland DW (2006) ALS: a disease of motor neurons and their nonneuronal neighbors. Neuron 52:39-59

Bruening W, Roy J, Giasson B, Figlewicz DA, Mushynski WE, Durham HD (1999) Upregulation of protein chaperones preserves viability of cells expressing toxic $\mathrm{Cu} / \mathrm{Zn}$-superoxide dismutase mutants associated with amyotrophic lateral sclerosis. J Neurochem 72:693-699

Bruijn LI, Becher MW, Lee MK, Anderson KL, Jenkins NA, Copeland NG, Sisodia SS, Rothstein JD, Borchelt DR, Price DL, Cleveland DW (1997) ALS-linked SOD1 mutant G85R mediates damage to astrocytes and promotes rapidly progressive disease with SOD1containing inclusions. Neuron 18:327-338

Cheroni C, Reviani P, Cascio S, DeBiasi C, Monti C, Bendotti C (2005) Accumulation of human SOD1 and ubiquitinated deposits in the spinal cord of SOD1G93A mice during motor neuron disease progression correlates with a decrease of proteasome. Neurobiol Dis 18 : $509-522$

Cheroni C, Marino M, Tortarolo M, Veglianese P, De BS, Fontana E, Zuccarello LV, Maynard CJ, Dantuma NP, Bendotti C (2009) Functional alterations of the ubiquitin-proteasome system in motor neurons of a mouse model of familial amyotrophic lateral sclerosis. Hum Mol Genet 18:82-96

Cheung EC, McBride HM, Slack RS (2007) Mitochondrial dynamics in the regulation of neuronal cell death. Apoptosis 12:979-992

Dal Canto MC, Gurney ME (1995) Neuropathological changes in two lines of mice carrying a transgene for mutant human $\mathrm{Cu}, \mathrm{Zn} \mathrm{SOD}$, and in mice overexpressing wild type human SOD: a model of familial amyotrophic lateral sclerosis (FALS). Brain Res 676:25-40

Daoud H, Dobrzeniecka S, Camu W, Meininger V, Dupre N, Dion PA, Rouleau GA (2013) Mutation analysis of PFN1 in familial amyotrophic lateral sclerosis patients. Neurobiol Aging 34(4):1311. doi:10.1016/j.neurobiolaging.2012.09.001, e1-2

Dejesus-Hernandez M, Mackenzie IR, Boeve BF, Boxer AL, Baker M, Rutherford NJ, Nicholson AM, Finch NA, Flynn H, Adamson J, Kouri N, Wojtas A, Sengdy P, Hsiung GY, Karydas A, Seeley WW, Josephs KA, Coppola G, Geschwind DH, Wszolek ZK, Feldman H, Knopman DS, Petersen RC, Miller BL, Dickson DW, Boylan KB, Graff-Radford NR, Rademakers R (2011) Expanded GGGGCC hexanucleotide repeat in noncoding region of C9ORF72 causes chromosome 9p-linked FTD and ALS. Neuron 72:245-256

Deng HX, Chen W, Hong ST, Boycott KM, Gorrie GH, Siddique N, Yang Y, Fecto F, Shi Y, Zhai H, Jiang H, Hirano M, Rampersaud E, Jansen
GH, Donkervoort S, Bigio EH, Brooks BR, Ajroud K, Sufit RL, Haines JL, Mugnaini E, Pericak-Vance MA, Siddique T (2011) Mutations in UBQLN2 cause dominant $\mathrm{X}$-linked juvenile and adult-onset ALS and ALS/dementia. Nature 477:211-215

Droppelmann CA, Wang J, Campos-Melo D, Keller B, Volkening K, Hegele RA, Strong MJ (2013) Detection of a novel frameshift mutation and regions with homozygosis within ARHGEF28 gene in familial amyotrophic lateral sclerosis. Amyotroph Lateral Scler Frontotemporal Degener 15:444-451

Durham HD, Roy J, Dong L, Figlewicz DA (1997) Aggregation of mutant $\mathrm{Cu} / \mathrm{Zn}$ superoxide dismutase proteins in a culture model of ALS. J Neuropathol Exp Neurol 56:523-530

Gehrig SM, van der Poel C, Sayer TA, Schertzer JD, Henstridge DC, Church JE, Lamon S, Russell AP, Davies KE, Febbraio MA, Lynch GS (2012) Hsp72 preserves muscle function and slows progression of severe muscular dystrophy. Nature 484:394-398

Gentil BJ, Minotti S, Beange M, Baloh RH, Julien JP, Durham HD (2011) Normal role of the low-molecular-weight neurofilament protein in mitochondrial dynamics and disruption in Charcot-Marie tooth disease. FASEB J 26:1194-1203

Hirano M, Nakamura Y, Saigoh K, Sakamoto H, Ueno S, Isono C, Miyamoto K, Akamatsu M, Mitsui Y, Kusunoki S (2013) Mutations in the gene encoding p62 in Japanese patients with amyotrophic lateral sclerosis. Neurology 80:458-463

Kabashi E, Agar JN, Taylor DM, Minotti S, Durham HD (2004) Focal dysfunction of the proteasome: a pathogenic factor in a mouse model of amyotrophic lateral sclerosis. J Neurochem 89:1325-1335

Kabashi E, Agar JN, Hong Y, Taylor DM, Minotti S, Figlewicz DA, Durham HD (2008) Proteasomes remain intact, but show early focal alteration in their composition in a mouse model of amyotrophic lateral sclerosis. J Neurochem 105:2353-2366

Kabashi E, Agar JN, Strong MJ, Durham HD (2012) Impaired proteasome function in sporadic amyotrophic lateral sclerosis. Amyotroph Lateral Scler 13:367-371

Kalmar B, Novoselov S, Gray A, Cheetham ME, Margulis B, Greensmith L (2008) Late stage treatment with arimoclomol delays disease progression and prevents protein aggregation in the SOD1 mouse model of ALS. J Neurochem 107:339-350

Karbowski M, Arnoult D, Chen H, Chan DC, Smith CL, Youle RJ (2004) Quantitation of mitochondrial dynamics by photolabeling of individual organelles shows that mitochondrial fusion is blocked during the Bax activation phase of apoptosis. J Cell Biol 164:493-499

Kieran D, Kalmar B, Dick JR, Riddoch-Contreras J, Burnstock G, Greensmith L (2004) Treatment with arimoclomol, a coinducer of heat shock proteins, delays disease progression in ALS mice. Nat Med 10:402-405

Kwiatkowski TJ Jr, Bosco DA, Leclerc AL, Tamrazian E, Vanderburg CR, Russ C, Davis A, Gilchrist J, Kasarskis EJ, Munsat T, Valdmanis P, Rouleau GA, Hosler BA, Cortelli P, de Jong PJ, Yoshinaga Y, Haines JL, Pericak-Vance MA, Yan J, Ticozzi N, Siddique T, Kenna-Yasek D, Sapp PC, Horvitz HR, Landers JE, Brown RH Jr (2009) Mutations in the FUS/TLS gene on chromosome 16 cause familial amyotrophic lateral sclerosis. Science 323: $1205-1208$

Labbadia J, Cunliffe H, Weiss A, Katsyuba E, Sathasivam K, Seredenina T, Woodman B, Moussaoui S, Frentzel S, Luthi-Carter R, Paganetti P, Bates GP (2011) Altered chromatin architecture underlies progressive impairment of the heat shock response in mouse models of Huntington disease. J Clin Invest 121:3306-3319

Magrane J, Sahawneh MA, Przedborski S, Estevez AG, Manfredi G (2012) Mitochondrial dynamics and bioenergetic dysfunction is associated with synaptic alterations in mutant SOD1 motor neurons. J Neurosci 32:229-242

Malik B, Nirmalananthan N, Gray AL, La Spada AR, Hanna MG, Greensmith L (2013) Co-induction of the heat shock response ameliorates disease progression in a mouse model of human spinal 
and bulbar muscular atrophy: implications for therapy. Brain 136: 926-943

Neumann M, Sampathu DM, Kwong LK, Truax AC, Micsenyi MC, Chou TT, Bruce J, Schuck T, Grossman M, Clark CM, McCluskey LF, Miller BL, Masliah E, Mackenzie IR, Feldman H, Feiden W, Kretzschmar HA, Trojanowski JQ, Lee VM (2006) Ubiquitinated TDP-43 in frontotemporal lobar degeneration and amyotrophic lateral sclerosis. Science 314:130-133

Nishimura AL, Mitne-Neto M, Silva HC, Richieri-Costa A, Middleton S, Cascio D, Kok F, Oliveira JR, Gillingwater T, Webb J, Skehel P, Zatz M (2004) A mutation in the vesicle-trafficking protein VAPB causes late-onset spinal muscular atrophy and amyotrophic lateral sclerosis. Am J Hum Genet 75:822-831

Renton AE, Majounie E, Waite A, Simon-Sanchez J, Rollinson S, Gibbs JR, Schymick JC, Laaksovirta H, van Swieten JC, Myllykangas L, Kalimo H, Paetau A, Abramzon Y, Remes AM, Kaganovich A, Scholz SW, Duckworth J, Ding J, Harmer DW, Hernandez DG, Johnson JO, Mok K, Ryten M, Trabzuni D, Guerreiro RJ, Orrell RW, Neal J, Murray A, Pearson J, Jansen IE, Sondervan D, Seelaar H, Blake D, Young K, Halliwell N, Callister JB, Toulson G, Richardson A, Gerhard A, Snowden J, Mann D, Neary D, Nalls MA, Peuralinna T, Jansson L, Isoviita VM, Kaivorinne AL, HolttaVuori M, Ikonen E, Sulkava R, Benatar M, Wuu J, Chio A, Restagno G, Borghero G, Sabatelli M, Heckerman D, Rogaeva E, Zinman L, Rothstein JD, Sendtner M, Drepper C, Eichler EE, Alkan C, Abdullaev Z, Pack SD, Dutra A, Pak E, Hardy J, Singleton A, Williams NM, Heutink P, Pickering-Brown S, Morris HR, Tienari PJ, Traynor BJ (2011) A hexanucleotide repeat expansion in C9ORF72 is the cause of chromosome 9p21-linked ALS-FTD. Neuron 72:257-268

Rosen DR, Siddique T, Patterson D, Figlewicz DA, Sapp P, Hentati A, Donaldson D, Goto J, O'Regan JP, Deng H-X, Rahmani Z, Krizus A, McKenna-Yasek D, Cayabyab A, Gaston SM, Berger R, Tanzi RE, Halperin JJ, Herzfeldt B, Van den Bergh R, Hung W-Y, Bird T, Deng G, Mulder DW, Smyth C, Laing NG, Soriano E, PericakVance MA, Haines J, Rouleau GA, Gusella JS, Horvitz HR, Brown $\mathrm{RH} \mathrm{Jr}$ (1993) Mutations in $\mathrm{Cu} / \mathrm{Zn}$ superoxide dismutase gene are associated with familial amyotrophic lateral sclerosis. Nature 362: $59-62$

Roy J, Minotti S, Dong L, Figlewicz DA, Durham HD (1998) Glutamate potentiates the toxicity of mutant $\mathrm{Cu} / \mathrm{Zn}$-superoxide dismutase in motor neurons by postsynaptic calcium-dependent mechanisms. J Neurosci 18:9673-9684

Shibata N, Hirano A, Kobayashi M, Asayama K, Umahara T, Komori T, Ikemoto A (1993) Immunohistochemical demonstration of $\mathrm{Cu} / \mathrm{Zn}$ superoxide dismutase in the spinal cord of patients with familial amyotrophic lateral sclerosis. Acta Histochem Cytochem 26:619622
Shimozono S, Fukano T, Nagai T, Kirino Y, Mizuno H, Miyawaki A (2002) Confocal imaging of subcellular $\mathrm{Ca}^{2+}$ concentrations using a dual-excitation ratiometric indicator based on green fluorescent protein. Sci STKE 125:14

Song W, Song Y, Kincaid B, Bossy B, Bossy-Wetzel E (2012) Mutant SOD1(G93A) triggers mitochondrial fragmentation in spinal cord motor neurons: neuroprotection by SIRT3 and PGC-1alpha. Neurobiol Dis $51: 72-81$

Tanaka K, Eskin A, Chareyre F, Jessen WJ, Manent J, Niwa-Kawakita M, Chen R, White CH, Vitte J, Jaffer ZM, Nelson SF, Rubenstein AE, Giovannini M (2013) Therapeutic potential of HSP90 inhibition for neurofibromatosis type 2. Clin Cancer Res 19:3856-3870

Tradewell ML, Cooper L, Minotti S, Durham HD (2011) Calcium dysregulation, mitochondrial pathology and protein aggregation in a culture model of amyotrophic lateral sclerosis: mechanistic relationship and differential sensitivity to intervention. Neurobiol Dis 42: 265-275

Tsvyetlynska NA, Hill RH, Grillner S (2005) Role of AMPA receptor desensitization and the side effects of a DMSO vehicle on reticulospinal EPSPs and locomotor activity. J Neurophysiol 94:3951-3960

Tummala H, Jung C, Tiwari A, Higgins CM, Hayward LJ, Xu Z (2005) Inhibition of chaperone activity is a shared property of several $\mathrm{Cu}$, $\mathrm{Zn}$-superoxide dismutase mutants that cause amyotrophic lateral sclerosis. J Biol Chem 280:17725-17731

Valdmanis PN, Daoud H, Dion PA, Rouleau GA (2009) Recent advances in the genetics of amyotrophic lateral sclerosis. Curr Neurol Neurosci Rep 9:198-205

Vance C, Rogelj B, Hortobagyi T, De Vos KJ, Nishimura AL, Sreedharan J, Hu X, Smith B, Ruddy D, Wright P, Ganesalingam J, Williams KL, Tripathi V, Al-Saraj S, Al-Chalabi A, Leigh PN, Blair IP, Nicholson G, De BJ, Gallo JM, Miller CC, Shaw CE (2009) Mutations in FUS, an RNA processing protein, cause familial amyotrophic lateral sclerosis type 6 . Science 323:1208-1211

Voellmy R (2004) On mechanisms that control heat shock transcription factor activity in metazoan cells. Cell Stress Chap 9:122-133

Wang C, Barluenga S, Koripelly GK, Fontaine JG, Chen R, Yu JC, Shen X, Chabala JC, Heck JV, Rubenstein A, Winssinger N (2009) Synthesis of pochoxime prodrugs as potent HSP90 inhibitors. Bioorg Med Chem Lett 19:3836-3840

Waza M, Adachi H, Katsuno M, Minamiyama M, Sang C, Tanaka F, Inukai A, Doyu M, Sobue G (2005) 17-AAG, an Hsp90 inhibitor, ameliorates polyglutamine-mediated motor neuron degeneration. Nat Med 11:1088-1095

Zhu H, Woolfenden S, Bronson RT, Jaffer ZM, Barluenga S, Winssinger N, Rubenstein AE, Chen R, Charest A (2010) The novel Hsp90 inhibitor NXD30001 induces tumor regression in a genetically engineered mouse model of glioblastoma multiforme. Mol Cancer Ther 9:2618-2626 